JANNAYNA MARTINS SALES

BIOÉTICA E VIOLÊNCIA DE GÊNERO NOS POVOS INDÍGENAS: DIAGNÓSTICO DE UMA NEGLIGÊNCIA.

Brasília, fevereiro de 2016 
UNIVERSIDADE DE BRASÍLIA

FACULDADE DE CIÊNCIAS DA SAÚDE

PROGRAMA DE PÓS-GRADUAÇÃO EM BIOÉTICA

JANNAYNA MARTINS SALES

BIOÉTICA E VIOLÊNCIA DE GÊNERO NOS POVOS INDÍGENAS: DIAGNÓSTICO DE UMA NEGLIGÊNCIA.

Dissertação apresentada como requisito parcial para obtenção do Título de Mestre em Bioética pelo Programa de Pós-graduação em Bioética da Universidade de Brasília

Orientador: Prof. Dr. Cláudio Lorenzo

BRASÍLIA

2016 


\title{
BIOÉTICA E VIOLÊNCIA DE GÊNERO NOS POVOS INDÍGENAS: DIAGNÓSTICO DE UMA NEGLIGÊNCIA.
}

\author{
Tese apresentada como requisito \\ parcial para obtenção do Título de \\ Mestra em Bioética pelo Programa \\ de Pós-Graduação em Bioética da \\ Universidade de Brasília.
}

Aprovada em:

BANCA EXAMINADORA

Cláudio Lorenzo - Presidente Universidade de Brasília

Aline Albuquerque Sant'Anna de Oliveira Membro titular interno ao programa Universidade de Brasília

Ximena PamelaDiaz Bermudez Membro titular externo ao programa Universidade de Brasília

Maria Gloria de Lima

Membro titular interno ao programa

Universidade de Brasília 
Às mulheres de garra que reescrevem a nossa história a partir de suas lutas e conquistas.

À minha mãe que me ensinou esse caminho como o caminho da sobrevivência. 


\section{AGRADECIMENTOS}

Agradeço imensamente ao meu orientador Prof. Dr. Claudio Lorenzo pelo

comprometimento, atenção e cuidado que me motivaram a buscar um crescimento constante;

Agradeço a minha família e amigos que me compreenderam e me acolheram em todas as etapas. 
Sonhe com o que você quiser. Vá para onde você queira ir. Seja o que você quer ser, porque você possui apenas uma vida e nela só temos uma chance de fazer aquilo que queremos. Tenha felicidade bastante para fazê-la doce. Dificuldades para fazê-la forte. Tristeza para fazê-la humana. E esperança suficiente para fazê-la feliz.

(Clarice Lispector) 


\section{Resumo}

As estatísticas sobre a violência de gênero tem sido impactantes e uma série de medidas políticas, jurídicas e institucionaistem sido desenvolvidas com a intenção de coibir o problema, obtendo até agora apenas uma discreta melhoria da situação. Entretanto, a questão da violência contra a mulher indígena não parece vir recebendo uma atenção especial, apesar delas virem denunciado em seus fóruns e movimentos as violências de que são vítimas. $O$ objetivo deste trabalho foi traçar um panorama sobre a abordagem dada pela produção científica nacional e por programas e políticas públicas brasileiros à violência de gênero no contexto dos povos indígenas e analisar seus resultados na perspectiva da Bioética Crítica. Utilizou-se como método a revisão integrativa, tal como proposta por Whittemore e Knalf. O levantamento da literatura teve por base os artigos científicos brasileiros indexados nas bases SCIELO e LILACS, usando-se os descritores "violência contra a mulher", "violência de gênero" e bioética", de forma separada e também em combinação com os descritores: "população indígena", "povos indígenas" e "indígenas". A escolha de programas e políticas foi feita por conveniência elegendoseaqueles relacionados à saúde e proteção dos povos indígenas e das mulheres.Dentre os 570 artigos encontrados, 66 atenderam aos critérios de inclusão e exclusão e fazem parte do estudo. Entre os resultados, vale notar que não foi encontrado nenhum artigodirigido ao problema específico da violência de gênero contra a mulher indígena. Apenas 7 abordaram em seus textos a necessidade de ampliar estudos para as populações indígenas e de considerar aspectos históricos e étnicos ao tratar do tema. Nenhum deles foi produzido a partir de uma perspectiva bioética. Quatro políticas e programas institucionais foram estudados. Todos abordaram, ao menos indiretamente o problema, mas não constavam de diretrizes ou ações específicas visando uma adequação intercultural das medidas. O referencial teórico com o qual os resultados foram discutidos foi sustentado na Bioética Crítica enquanto campo reflexivo e de compromisso prático com a transformação da realidade e emancipação de grupos em desvantagens sociais historicamente determinadas. É dado ênfase também aos estudos de colonialidade a partir dos quais a negligência identificada foi atribuída à uma colonialidade de saber e de poder. Conclui-se que a crueldade e o desamparo às mulheres vítimas de violência aumentam conforme avança a concepção de Estado moderno e o livre mercado e com esse panorama invisível e negligente promove uma grande lacuna a ser preenchida por estudos nessa área. Considera-se ainda, a necessidade de construções descoloniais de caminhos plurais tanto para o campo científico quanto para as políticas públicas, leis e redes de proteção institucionais, o que implica também uma dimensão ética da abertura de espaços de diálogos interculturais com olhar transformador sobre as estruturas e as relações sociais de gênero. $\mathrm{O}$ estudo conclui pela necessidade da divulgação da invisibilidade científica einstitucional detectadase propõe, entre outros caminhos, uma maior inserção do tema nas graduações e pós-graduações tanto na bioética quanto em saúde pública; desenvolvimento de editais específicos para estudos etnográficos sobre relações de gênero, ampliação de estudos em boletins de ocorrência focando os registros de violência de gênero em contexto indígena, e, muito especialmente, a promoção de 
espaços e fóruns a partir dos quais as próprias mulheres construam ações e redes de saberes e de proteção intracomunitárias culturalmente adequadas.

Palavras-Chave: Violência de gênero. Povos indígenas. Colonialismo. Bioética crítica.

\section{ABSTRACT}

Gender-based violence statistics have been striking the society with important numbers so a series of political, legal and institutional measures have been developed with the intention to restrain the problem, resulting only on a slight improvement in the situation. Violence against indigenous women on another account doesn't seem to be receiving any special attention, although these women have been reporting in forums and through specific social movements all the violence they suffer. The objective of this study was to establish an overview of the approach taken by the Brazilian scientific production and both public programs and policies on gender-based violence in the context of indigenous peoples and analyze its results in the perspective of Critical Bioethics. It was used an integrative review as proposed by Whittemore and Knalf. The literature review was based on the Brazilian scientific articles indexed in SCIELO and LILACS, using the following descriptors "violence against women", "gender violence" and bioethics ", separately and in combination with the following keywords: "indigenous peoples", "indigenous population" and "indigenous". The choice of programs and policies was made by convenience in order to elect those related to either health or protection of indigenous peoples and women. Among the 570 articles found, 66 met both the inclusion and exclusion criteria to be part of the study. Among the results, no article addressed the specific issue of gender violence against indigenous women was found.and only 7 addressed in its considerations the need to expand studies to indigenous populations and to consider historical and ethnic aspects when addressing the issue. None of them was produced from a Bioethical perspective. Four political and institutional programs were studied. All covered, at least indirectly, the problem, but didn't contain specific guidelines or actions to an intercultural appropriateness of the guidelines. The theoretical framework with which the results were discussed was held based on a Critical Bioethics as a reflective field and a practical commitment to the transformation of reality and emancipation of groups singled out by an historically determined social disadvantage. We also emphasize colonialism studies from which the identified negligence was attributed to one's colonialism of knowledge and power. We conclude that the cruelty and the helplessness to women victims of violence increases as the conception of the modern state and the free market move forward and this invisible and negligent panorama promotes a large gap to be filled by studies in this area. It also considers the need for non colonialist buildings of plural paths both for the scientific field and to public policies, laws and institutional safety nets, which also implies in an ethical dimension of opening spaces for intercultural dialogue with a changing overview on structures and social relations of gender. The study concludes the need to point out the scientific and institutional invisibility of the chosen subject and proposes greater integration of the theme at the undergraduate and postgraduate courses both in bioethics and in public health; the development of 
specific notices to ethnographic studies on gender relations, expanded studies in police reports focusing on gender violence records in the indigenous perspective and the promotion and dissemination of spaces and forums from which women themselves can build actions and networks of knowledge and culturally appropriate intra protection.

Keywords: Gender violence. Indian people.Colonialism.critical bioethics. 


\section{Lista de Quadros}

Quadro 1. Variáveis relacionadas ao ano de publicação, à categoria de objetivos, à citação ou abordagem à questão intercultural/mulher indígena e aos aspectos éticos ou bioéticosabordados

Quadro 2. Porcentagem de produção científica no tema por região e estados e categoria de objetivos

Quadro 3. Políticas e programas relacionados à saúde indígena, saúde da mulher e violência de gênero, quanto à presença ou não de abordagem específica da violência de gênero no contexto dos povos indígenas 


\section{Lista de Abreviaturas e Siglas}

SCIELO - Scientific Eletronic Library Online

LILACS - Literatura Latino-Americana e do Caribe em Ciências da Saúde

PNASPI - Política Nacional de Atenção à Saúde dos Povos Indígenas

PNASM - Política Nacional de Atenção Integral à Saúde da Mulher

PNEVCM - Pacto Nacional de Enfrentamento à Violência Contra as Mulheres

PNPM - Plano Nacional de Políticas para as Mulheres

SUS - Sistema Único de Saúde

CRAM - Centros de Referência de Atendimento à Mulher

CREAS - Centros de Referência Especializados de Assistência Social

CUT - Central Única dos Trabalhadores

AMNB - Articulação de Organizações de Mulheres Negras

SPM-PR - Secretaria de Políticas Para Mulheres

CEDAW - Convenção sobre a eliminação de todas as formas de discriminação contra a mulher 


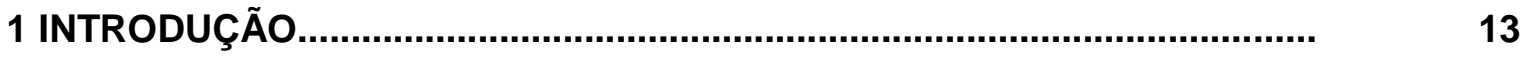

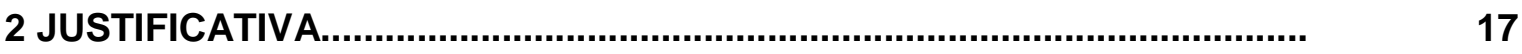

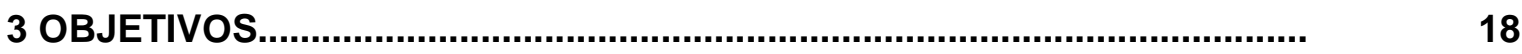

4 REVISÃO DE LITERATURA E REFERENCIAL TEÓRICO........................... 19

4.1 Violência de Gênero: Conceitos e Tipificações .....................................

4.2 Panorama da Violência de Gênero no Brasil e seu Alcance.................. 23

4.3 Bioética Crítica..................................................................................

4.4 Estudos sobre Colonialidade: Colonialidade do Poder e do Saber.... 30

4.5 Interculturalidade e Direitos Humanos..................................................

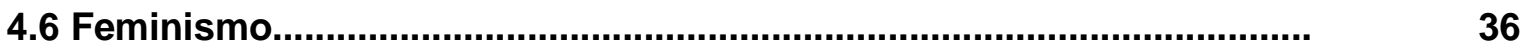

5 METODOLOGIA ……..................................................................

6 RESULTADOS E DISCUSSÃO_...............................................................

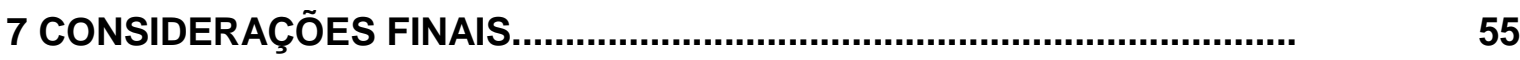

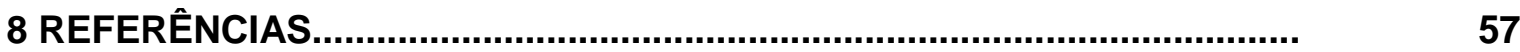




\section{INTRODUÇÃO}

Os impactos da violência física, psicológica ou simbólica sobre a saúde das mulheres têm sido amplamente discutidos na literatura brasileira e internacional. O Brasil ocupa o $7^{0}$ lugar no ranking mundial de violência contra mulheres em uma lista de 84 países, ficando atrás apenas da Colômbia na América Latina e sustentando um índice de 4,4 assassinatos para cada 100 mil mulheres(1).

É alarmante o fato de que $48 \%$ das mulheres são vítimas de violência em sua própria casa (2).Cerca de $20 \%$ dos filhos são vítimas diretas com as mães (3) e é também comum que, mesmo quando não são fisicamente agredidas, as crianças presenciem as cenas de violência. As implicações dessas experiências tendem a se refletir na naturalização do comportamento agressivo e na reprodução da violência em seus futuros relacionamentos ou círculos sociais.

No Brasil, desde a promulgação da Lei Maria da Penha, em 2006,o combate à violência contra a mulher obteve avanços no que se refere ao aumento de denúncias por parte das mulheres e à criação de mecanismos sociais para sua repressão. Entretanto, números atuais mostram que ainda há muito a se fazer.

O crime de feminicídio, por exemplo, teveapenas um pequeno declínio em 2007, saindo do patamar de 4,6 mortes por 100 mil mulheres para 4,5, mas em 2010 esse índice já havia voltado a crescer (4). A recente tipificação do feminicídio como crime hediondo, impondo diversos agravantes à condenação, tornou-se outro importante instrumento jurídico de combate.

Na esfera do Poder Executivo, o Plano Nacional de Políticas para Mulheres, lançado em 2005, instituiu uma Rede de Atendimento a Mulheres em Situação de Violência, que articula ações e serviços nas áreas de assistência social, justiça, segurança pública e saúde (5).Esta rede busca assegurar, a partir de estruturas administrativas de atendimento sensíveis às situações em que as mulheres vítimas da violência se encontram, a identificação e os encaminhamentos adequados, além da integralidade e humanização da assistência. Será composta por serviços especializados, como os Centros de Referência de Atendimento à Mulher (CRAM) e 
os Centros de Referência Especializados de Assistência Social (CREAS) e nãoespecializados, necessárias ao atendimento.

Não obstante os avanços que têm sido alcançados na estruturação do combate à violência contra a mulher, o novo aparato jurídico-estatal não parece vir sendo pensado para abarcar a diversidade cultural do nosso país, em especial no que se refere aos povos indígenas. A Lei Maria da Penha universaliza o tratamento em relação à etnia/raça, mas não alcança as diversidades encontradas nos indígenas,particularmente quantoaos sistemas jurídicos próprios e às redes comunitárias de proteção.

Lorenzo (6), em abordagem bioética sobre a formulação de políticas públicas,ressalta que no contexto sociopolítico de elaboração das políticas públicas é necessário que se conheçam os sujeitos demandantes e suas principais necessidades, de modo a se respeitar a diversidade entre os grupos alvo das políticas. Segundo ele,tanto a matriz simbólica de compreensão do processo de saúde-doença como a matriz cultural dos grupos sociais e étnicos excluídos são diferenciadas daquela em que o formulador se estabelece. Desconsiderar esses elementos pode potencializar as situações vulneráveis nas quais estes vivem.

Assim, mais que ações programáticas ou de transposição de leis, entendemos que seja necessário estabelecer processos de formulação participativos e que levem, como diz Lorenzo, a condicionar os grupos alvo, de modo a capacitálos para se realizarem plenamente, no que diz respeito não só ao acesso a oportunidades, bens e serviços, como também às possiblidades de escolha. Caso contrário, ressalta o autor, o modelo que prega o "autoritarismo médico-científico" e o "etnocentrismomoral e político"será fortalecido.

Neste sentido, não seria adequado fazer uma simples transposição das leis e das ações programáticas previstas pelas políticas públicas para a prevenção, denúncia e responsabilização, sem considerar o universo cultural e social dos diversos povos. Sua adequada aplicação não pode prescindir de estudos antropológicos sobre relações de gênero, sobre compreensão cultural das causas e consequências da violência e sobre formação intracomunitária de mecanismos de enfrentamento. A elaboração das vias de aplicação dos aparatos de proteção e de outras formas de combate culturalmente mediadas demandaria, além da aplicação dos saberes construídos a partir de estudos etnográficos, a abertura de amplos 
fóruns de discussão onde as mulheres indígenas fossem ouvidas e propusessem caminhos.

Os estudos socioantropológicos que investigam as relações entre violência de gênero e justiça têm procurado discutir como se dão as hierarquias sociais e de gênero e conhecer como as mulheres são vitimizadas tanto no seu âmbito familiar quanto por estruturas de poder, como o Estado. Mas não parecem ser frequentes estudos dedicados à questão da mulher indígena.

Segato (7) chama a atenção sobre a inexistência de evidências quanto à incidência e às diversas formas de violência às quais as mulheres indígenas têm sido historicamente submetidas, devido à escassez de estudos antropológicos sobre as relações de gênero entre os povos indígenas na América Latina. No Brasil, talvez em função da pequena proporção de indígenas na população, estudos dessa natureza são ainda mais escassos.Já na literatura internacional encontra-se, com maior frequência, tanto estudos etnográficos quanto ensaios teóricos sobre a questão, a exemplo dos que buscam compreender a percepção das mulheres indígenas sobre a rede estatal de assistência e proteção (8),analisar a articulação histórica entre patriarcalismo, colonialismo e capitalismo dentro do processo de globalização como origem de diversos tipos de violência contra a mulher indígena (9) ou criticar a tendência colonial no discurso antiviolência de algumas correntes do feminismo em relação às mulheres indígenas (10).

No Brasil, conforme censo do Instituto Brasileiro de Geografia e Estatística IBGE em 2010 (35), havia817.963 pessoas se declararam indígenas. Isso representava menos de $0,5 \%$ da população geral do Brasil.

De acordo com estudo especial do IBGE, divulgado em 2012, o crescimento da população indígena no Brasil no período 2010/2000 não foi significativo quandocomparado ao período 1991/2000. Este apresentou aumento de 150\%, contra apenas $11,4 \%$ daquele.

Ainda assim, o Brasil se destaca na América do Sul por seu "significativo contingente" de indígenas. Destaca-se também pela "miscigenação entre os diversos grupos étnicos", que "deu origem a tão numerosas e complicadas combinações que se torna impossível chegar a uma classificação étnica dos brasileiros" (36). 
O Censo de 2010 mostra que diminuiu o número de pessoas autodeclaradas como indígenas nas zonas urbanas. Isso pode ser um indicativo de que, nessas áreas, as populações indígenas se tornam invisíveis por influências culturais das grandes cidades, para que sejam integrados à essa esfera. Mas, quando são atraídas para as regiões periféricas ou ainda de volta para suas comunidades, também pode indicar um processo etnoculturalinjusto de desempoderamento, como descreve Kymlicka (37), ao tratar do processo migratório e imigratório cultural.

O que parece claro, seja no Brasil seja na maioria os países com populações indígenas, é que a organização e as relações de poder dentro das comunidades vêm sofrendo influências das concepções de modernidade para alterar padrões culturais e históricos de interação entre os gêneros. Além de favorecer as práticas de violência, isso dificulta o encontro de soluções culturalmente mediadas. Pois o imperativo moral que conduz os homens a serem cada vez mais sujeitos masculinos e que os força a comportamentosque provem habilidades de resistência, agressividade e que demonstrem forças bélicas, políticas, sexual, econômica e moral tem como consequência o comportamento violento do homem sobre a mulher (7).

As mulheres indígenas, por meio de associações civis, já vêm denunciando as violências que sofrem em suas comunidades. Em fóruns realizados em Roraima as mulheres declaram que "Cresce a violência contra os povos indígenas e suas lideranças. Neste cenário, destaca-se a grande vulnerabilidade, pelas várias formas de violência que as mulheres e as crianças indígenas sofrem: física, moral, psicológica, entre outras"(11).

EmMato Grosso (12) e em Brasília (13),por meio de encontros e oficinas de trabalho para discutir as pautas das mulheres indígenas, elas fizeram apelo por providências do Estado sobre as causas que levam os homens de suas aldeias a cometer violências, em especial o alcoolismo, mal moderno que,segundo elas,seduz os homens e os levam a práticas violentas.

Outros estudos(14)(15) já apontam que as mulheres indígenas são vítimas de violência principalmente pela relação direta com situações que rompem suas organizações sociais, como as perdas territoriais e a ruptura dos vínculos sociais, políticos, econômicos e religiosos que as colocam em situação de vulnerabilidade. 
A Bioética constitui-secomodisciplina produtora e modificadora da história, reforçando o papel político e de respeito às culturas a partir dos significados e símbolos de cada uma para a resolução de problemas. Nesse sentido, não pode se ater a análises principialistas ou doutrinárias previamente definidas (17). É também tarefa da Bioética a abordagem crítica da ciência, de seus interesses e produções, bem como das consequências sociais das mesmas.

A presente dissertação tem a finalidade de fazer uma revisão integrativa das publicações científicas brasileiras sobre violência de gênero, com foco na mulher indígena e nos programas e políticas públicas direcionadas à saúde e à proteção da mulher indígena. Busca identificar oque tem sido proposto pela comunidade científica e pelo Estado para a abordagem do problema neste contexto de interculturalidade. Os resultados dessa revisão são analisados na perspectiva da Bioética Crítica. 


\section{JUSTIFICATIVA}

Em face do conjunto de demandas reconhecidas pelas mulheres indígenas e do evidente desenvolvimento de políticas públicas que incentivam ações de combate à violência, há um conflito entre as formas de adequação cultural que exige uma análise aplicada que ilumine caminhos culturalmente adequados, dialogados e plurais. Neste sentido, a Bioética como campo de ética aplicada é um espaçoapropriado para a análise dos conflitos característicos ao enfrentamento da violência de gênero contra as mulheres indígenas, à percepção científica do problema e à adequada aplicação de instrumentos políticos-institucionais para seu equacionamento.

A bioética, segundo Garrafa (18), tem se dedicado, especialmente na América Latina, a construir referências públicas e a promover a participação direta de atores sociais na análise das responsabilidades de saúde e no reconhecimento da trajetória histórica e social das pessoas. Essa interpretação não se restringe à esfera privada, alcançando o espaço social compartilhado, em especial aquele relacionado às questões que envolvem os grupos mais frágeis e necessitados.

Nesse contexto, um estudo bioético sobre a abordagem dada à violência contra a mulher indígena, avaliando a produção científica nacional e as políticas institucionais de apoio, poderá dimensionar demandas por atuações culturalmente adequadas. Poderá também contribuir para a formulação e implementação de redes de proteção baseadas em uma construção dialógica intracomunitária. 


\section{OBJETIVOS}

\section{Geral:}

Traçar um panorama sobre a abordagem dada pela produção científicae por programas e políticas públicas brasileiras à violência de gênero no contexto dos povos indígenas e analisar seus resultados na perspectiva da Bioética Crítica.

\section{Específicos:}

a) Produzir uma ampla revisão dos artigos científicos publicados no período de 2000 a 2015 nas bases SCIELO e LILACS sobre violência de gênero;

b) Investigar quais os objetivos principais dessa produção e as regiões em que foram produzidas por comparação aos índices de violência de gênero e à presença de povos indígenas;

c)Avaliar diretrizes e ações propostas por programas e políticas públicas relacionados à saúde da mulher indígena eà proteção contra violência de gênero;

d) Analisar, a partir de uma perspectiva bioética critica intercultural e descolonial, a abordagem dada às questões interculturais e, em especial, à violência contra a mulher indígena. 


\section{REVISÃO DE LITERATURA E REFERENCIAL TEÓRICO}

\subsection{Violência de Gênero: Conceitos e Tipificações}

Entendemos gênero como algo que se constitui a partir do conjunto de relações, atributos, papéis, crenças e atitudes(19) que permitem melhor compreensão sobre papeis de mulheres e homens na vida social. Desde logo, cabe ressaltar que tal entendimento se distanciada antiga conceituaçãode base biológica(20).

Este conceito possibilita compreender como o gênero é influenciado pelasrelações de poder entre o homem e a mulher. Por consequência, possibilita também compreender como o gênero está sujeito a desigualdades e violências que desestabilizam atributos, papéis, crenças e atitudes típicas da mulher na sociedade.

$\mathrm{Na}$ antropologia,como já apontado, os estudos que investigam as relações entre violência de gênero e justiça têm discutido não só como se dão as hierarquias sociais e de gênero, mas também como as mulheres são vitimizadas no âmbito familiar e em estruturas de poder, como o Estado (21).Ainda assim, não há entre os etnólogos um consenso sobre a questão de gênero. Como aponta Segato (7), a posição predominante da antropologia no Brasil é a de que a discussão de gênero em comunidades indígenas subordina-se a estudos de parentesco e de família e que, em geral, há muita reserva entre os etnólogos brasileiros quanto à questão de gênero no mundo indígena. Segundo a autora, haveria disputas políticas e de minorias - diretos humanos e direitos das mulheres - espúrias e impostas do exterior pela visão do mundo aldeia. Isso tem tido como consequência a escassez de estudos etnográficos dessa natureza.

No campo social, a violência de gênero é estudada com o olhar voltado para a violência doméstica, sexual e familiar. Mas já há estudos específicos sobre a reflexão da ausência de mulheres em espaços institucionais, sobre o machismo e o assédio sexual e moral que as mulheres sofrem e sobre a responsabilidade que as mulheres detém em seus espaços de vida privada e familiar (22). 
Já no campo do direito (23), a violência de gênero adquire caráter específico por causa da judicialização das relações sociais e da contínua incursão do direito na vida social, por meio de normativas que regulam o comportamento social. Muitas vezes,o julgamento se faz a partir do olhar crítico às mulheres vítimas de violências, como se estas tivessem sido motivadaspor problemas como falta de confiança, baixa autoestima ou dificuldades de comunicação por parte das mulheres.

Em termos de tipificação legal, a Lei Maria da Penha (24)criou mecanismos para coibir e prevenir a violência doméstica e familiar contra a mulher, pois foi concebida a partir da realidade de violência vivenciada por mulheres inseridas em um espaço poder ocupado predominantemente pelo homem. Esse espaço é o da esfera privada e o do convívio no âmbito da família, como comunidade constituída por parentesco ou por laços naturais, afinidades ou vontades expressasem qualquer relação íntima de afeto.

A Lei Maria da Penha também inovou ao trazer conceitos e tipificações das formas de violência doméstica e familiar contra a mulher, como a violência psicológica, moral e patrimonial, além da violência física e sexual. Diante dessa caracterização, especificou mecanismos do Estado a serem disponibilizados para coibir essas práticas, como campanhas educativas e de comunicação sobre a violência e o preconceito pelo qual as vítimas são submetidas. Além disso, propôs o desenvolvimento de estudos sobre o fenômeno da violência contra mulher, inclusive na perspectiva de gênero, raça ou etnia.

A Lei Maria da Penha propôs ainda outras ações articuladas com diferentes entes e órgãos do Estado, voltadas para a assistência à vítima da violência,como ações de proteção pessoal imediata, inclusive de vínculos trabalhistas. Há também partes da leidedicadas ao procedimento e à atuação das autoridades legais, sejam policiais, jurisdicionais ou assistenciais, de modo a constituir estruturas administrativas para o recebimento, o tratamento e o julgamento de atos de violência doméstica e familiar contra a mulher. Nesse contexto, cabe destacar a criação de centros de atendimento integral e multidisciplinar, a constituição de casas-abrigo e a abertura de delegacias, núcleos e defensorias especializadas.

Por tudo isso, a Lei Maria da Penha representa um avanço importante no combate a todas as formas de violência de gênero, dando visibilidade e materialidade àquilo que antes era tratado na intimidade das mulheres e de suas 
famílias como algo a ser tolerado e velado. Nesses espaços de intimidade, como se sabe,háuma grande influência da cultura e dos valores éticos e morais advindos da família. Em alguns momentos, as mulheres não têm clareza sobre as formas de violência e de dominação e, por isso, acabam se submetendo à chantagem do discurso de "sempre foi assim" por medo de perder sua identidade, seu capital político, sua cultura e seu capital simbólico, na família e em outros grupos sociais. $\mathrm{Na}$ verdade, porém, romper com esse falso discurso é alcançar conquistas descoloniais e emancipatórias (25).

Ainda que tente abarcar questões éticas quando trata das ações de prevenção, a Lei Maria da Penha não pode alcançar o reconhecimento da necessidade de considerar as questões éticas morais e culturais, por se um dispositivo legal. Entretanto, isso seria uma forma de reforçar a necessidade de contextualizar e inserir em sua aplicação outras realidades, não reconhecidas pelo senso comum, a exemplo da violência sofrida por mulheres indígenas.

De acordo com Castilho (26),representante do Ministério Público que participou da elaboração da proposta da Lei Maria da Penha, esta não prevê tratamentos diferenciados para culturas diferenciados. Isso reforça os desafios que se apresentam ao lidarmos com a questão da violência de gênero em comunidades com culturas e valores diferentes dos nossos, nas quais a interpretação do rigor da lei pode divergir de suas leis internas.

Recentemente, outro dispositivo trouxe novas tipificações legais de proteção à violências contra mulheres. Trata-se da Lei no 13.104 de março de 2015 (27), denominada Lei do Feminicídio, que altera o Código Penal para prever que o feminicídio seja circunstância qualificadora do crime de homicídio, transformando, assim, o homicídio de mulheres em crime hediondo.

Ainda que a nova lei não seja suficiente para solucionar o problema das mortes das mulheres, três pontos merecem ser destacados. O primeiro diz respeito ao próprio conceito de feminicídio, ali identificado como crimes "contra a mulher por razões da condição de sexo feminino", que parece indicar uma possibilidade de incompreensão do termo "gênero",no sentidoamplo, aqui utilizado para se referir a todas as formas sociais marcadas pela presença do feminino, não se restringindo apenas ao órgão sexual feminino. O segundo ponto diz respeito à ampliação da esfera de atuação legal, pois se a Lei Maria da Penha se dedicava exclusivamente à 
violência doméstica e familiar ocorridas em âmbito familiar ou íntimo, a aplicação da Lei do Feminicídio se expande para a esfera pública quando esta se refere a crimes de menosprezo ou discriminação à condição de mulher, incluindo o homicídio por extermínio. Por fim, o terceiro ponto diz respeito ao agravamento da pena nos casos de crimes que envolvem crianças e idosas, que é a grande marca da Lei do Feminicídio.

Com o tempo, essas e outras novas formas jurídicas permitirãoo desenvolvimento de mecanismos sociais mais eficazes de proteção e defesa às vítimas de violência de gênero. Trata-se de uma possibilidade, pois o problema ainda se configura pouco visível na sociedade brasileira.

Mas alguns movimentos sociais e populares no país já mostram sensibilidade à questão da violência de gênero. É o caso do Movimento dos Sem Terra MST(28),para quem a luta em defesa das mulheres vítimas de violência no campohoje representa também uma frente de resistência contra a sociedade patriarcal, capitalista, que tem na posse da terra uma de suas principais fontes de poder econômico e político.

A Rede Nacional Feminista de Saúde, Direitos Sexuais e Reprodutivos (Rede Feminista de Saúde) já considerava a violência de gênero como problema mundial há 14 anos, quando elaboraram o Dossiê Violência Contra a Mulher (29). O documento não só apontava a relação de poder masculino como elemento chave na violência contra mulheres, como também reconhecia que a violência doméstica e sexual eram formas históricas de violência às quais vieram a se associar mais recentemente outras formas de violência, como as diferenças remuneratórias, as diferenças nos atendimentos em saúde eo assédio sexual no trabalho. Apontava ainda um ponto extremamente importante: a invisibilidade do tema. Indicativa da incompatibilidade da lei com a prática social, a referida invisibilidade está relacionada com uma suposta inexistência do problema da violência de gênero ou com o fato de tal problema não poder ser discutido na esfera pública. Isso manteria a violência de gênero como problema invisível perante a sociedade, a ser escondido na intimidade da mulher e em seu convívio familiar.

Recentemente, a Central Única dos Trabalhadores - CUT organizou o $8^{\text {o }}$ Encontro Nacional de Mulheres da CUT (30), evento no qual a necessidade de reforçar a luta pela igualdade e pela liberdade das mulheres foi tema amplamente 
debatida. O texto-base do encontro afirmava que a violência de gênero na sociedade brasileira deve ser enfrentadacomo problema social, não como problema individual. Essa constatação levou o movimento sindical a atuar no combate à violência contra as mulheres, ampliando o seu espaço de lutas para além daquele tradicionalmente reservado às questões trabalhistas.

AArticulação de Organizações de Mulheres Negras Brasileiras - AMNB (31) considera quea questão da violência de gênero é mais grave entre as mulheres negras por comparação às mulheres brancas. O número de homicídios entre as primeiras, por exemplo, é bem maior que aquele registrado entre as últimas. Isso revela, para além da gravidade da situação de violência contra as mulheres negras no país, também a persistência do racismo como problema ainda invisível aos olhos da sociedade e do Estado brasileiros.

Diante do conjunto de conceitos e tipificações dados à questão da violência de gênero e da amplitude de campos de estudo e movimentos sociais organizados envolvidos em seu enfrentamento, podemos concluir que ainda não se fazem visíveis no Brasil ações político-institucionais e de reconhecimento científico que dialoguem no sentido de adequação à diversidade cultural.

\subsection{Panorama da Violência de Gênero no Brasil e seu Alcance}

Desde a aprovação da Lei Maria da Penha, em 2006, o combate à violência contra a mulher no Brasil tem tido avanços em suas denúncias e na sua repressão. Entretanto,os números atuais mostram que ainda muito se precisa fazer para reduzir a violência contra mulheres e, principalmente,para enfrentar suas principais causas.

Segundo dados da Secretaria de Políticas para as Mulheres da Presidência da República - SPM-PR (3), referentes a 52.957 casos registrados em 2014, as denúncias sobre violência contra a mulher no Brasil são assim distribuídas: Violência física $51,7 \%$; Violência psicológica $31,8 \%$; Violência moral $9,7 \%$; Violência patrimonial 1,9\%; Violência sexual 2,9\%; Cárcere privado 1,8\%; Envolvendo tráfico $0,4 \%$.

Os dados revelam ainda que a violência de gênero teve um singelo declínio em 2007, saindo do patamar de 4,6 mortes por 100 mil mulheres para 4,5 (4). Mas essa redução é insignificante diante da magnitude do problema, tanto que em 2010 esse índice volta a crescer. 
Segundo dados do Mapa de Violência (1),de 2013, as taxas de homicídio de mulheres (por 100 mil) são altamente preocupantes nos seguintes estados brasileiros: Roraima (15,3); Espirito Santo (9,3); Goiás (8,6); Alagoas (8,6); Acre $(8,3)$; Paraíba $(6,4)$; Rondônia $(6,3)$; Ceará $(6,2)$; Mato Grosso do Sul $(5,9)$ e Pará $(5,8)$. Dentre estes estados, pelo menos três têm grande contingente de indígenas: Pará, Roraima e Mato Grosso do Sul.

Esses números demonstram a grande intolerância existenteeseu resultado em termos de violências de gênero.No Balanço do Disque 180 (3), apresentado em 2015, os relatos de violência contra a mulher são apresentados principalmente por mulheres negras $(58,5 \%)$, seguidas por mulheres brancas $(40,5 \%)$, por mulheres amarelas $(0,5 \%)$ e por mulheres indígenas $(0,4 \%)$. Infelizmente, o estudo do Mapa da Violência não desagregou o contingente de mulheres negras, que inclui mulheres que se declararam como pretas ou pardas, contrapondo esse total ao das mulheres brancas.

Para enfrentar a violência de gênero, estruturas de proteção à mulher são constituídas a partir de políticas públicas que fazem previsão de planos de defesa e de combate a determinados problemas de grupos ou minorias específicas. O Plano Nacional de Políticas para Mulheres (5), por exemplo, definiu objetivos e estratégias para o fortalecimento das questões relacionadas à mulher. Dentre as ações previstaspara esse fim, destaca-se a estruturação de uma Rede de Atendimento a Mulheres em Situação de Violência, a partir da articulação de ações e serviços nas áreas de assistência social,justiça, segurança pública e saúde.

Areferida rede deve contemplar estruturas administrativas de atendimento e que sejam sensíveis às situações em que as mulheres vítimas da violência se encontram. Busca-se proceder à identificação e aos encaminhamentos adequados, de modo a assegurar a integralidade e a humanização da assistência por meio de um amplo conjunto de instituições governamentais. Além de serviços especializados, como os Centros de Referência de Atendimento à Mulher (CRAM) e os Centros de Referência Especializados de Assistência Social (CREAS), deverá contar também com serviços não-especializados, como os Centros de Referência de Assistência Social (CRAS) (2).

Na perspectiva dos direitos humanos, a proteção contra a violência de gênero tem sido abordada pela Convenção sobre a Eliminação de Todas as Formas de 
Discriminação contra a Mulher - CEDAW. Trata-se do o primeiro texto específico em defesa das mulheres, no qual se afirmou o compromisso por parte dos Estados em garantir igualdade de direitos econômicos, sociais, culturais, civis e políticos, além de tratar da eliminação das diferentes formas de discriminação, sejam elas políticas, econômicas, sociais, culturais ou civis (32). Há ainda a Convenção de Belém do Pará, que trata da proteção das mulheres contra todos os atos de violência, inclusive atos de violação de direitos humanos e liberdades fundamentais (33).

A violência de gênero está intimamente ligada a fatores como o machismo (46\%) e o alcoolismo (31\%) (34). Nesse contexto, não é difícil entender que as motivações se marcam pela constituição de relações de poder que se estabelecem a partir do pensamento masculino de dominação, seja pela cultura do homem como representação do poder perante a mulher, seja pela dominação exercida por ele encorajada pelo alcoolismo. Isso remete à relação patriarcal estabelecida há séculos, ainda vigente na atualidade como mecanismo de dominação baseado no poder do pai sobre os filhos e dos jovens aos mais velhos, na necessidade de divisão social e do trabalho. Apesar do avanço da conquista de direitos por parte das mulheres, essa relação tem sido ampliada para o poder do homem sobre a mulher, cabendo a ele prover a unidade doméstica e aela, a tarefa de cuidado do lar e dos filhos.

Atualmente, as famílias adquiriram novas configurações, mas isso não impediu o patriarcado de se atualizar subjetivamente para se adaptar. De fato, as mulheres são responsáveis também por prover. Além de dividir o trabalho, cuidam dos filhos e do lar. Mas estão sujeitas às imposições dos homens e ainda se sentem culpadas por não serem completas em suas " atribuições". Tais mudanças também alcançaram as comunidades indígenas.

\subsection{Bioética Crítica}

Nesse item, discutiremos a Bioética Critica como sustentação teórica e caminho analítico para abordar a questão da violência de gênero em mulheres indígenas. Em seguida, discorreremos sobre a relação de colonialidade do poder e do saber que contorna o problema. Por fim, descreveremos os papeis que 0 
feminismo, a interculturalidade e os Direitos Humanos desempenham na discussão sobre a violência de gênero.

A Bioética Critica é calçada na Teoria Crítica da Escola de Frankfurt e é apresentada por Lorenzo (16), em seu exercício de fundamentação, por conter, fundamentos analíticos e prescritivos para a bioética. Entretanto, o autor alerta que seu exercício inicial carece de empenho na adequação da teoria ao contexto cultural latino-americano e, para tanto, propõe uma costura teórica com os referenciais dos Estudos da Colonialidade.

Instaurada no Instituto de Pesquisa Social da Universidade de Frankfurt e disseminada por Max Horkheimer (38) a partir do marxismo,a Teoria Crítica tem como característica a posição questionadora sobre a teoria tradicional, cujo principal objetivo era a expansão dos mercados capitalistas e o aumento da capacidade de exploração a partir da produção de conhecimento e de tecnologias (16). Nesse sentido, pensar problemas bioéticos a partir da teoria crítica pode qualificar a análisea partir de um olhar criterioso, reflexivo, politizado e comprometido com a mudança da realidade.

A Escola se concretizou a partir de um grupo de intelectuais vinculados ao Instituto de Pesquisa Social da Universidade de Frankfurt, em 1923. Sua história é marcada pela criação e consolidação do Instituto, entre 1922 e 1932; pela migração dos seus fundadores (Benjamim, Horkheimer, Adorno e Marcuse) para a Suíça e os EUA, durante o período nazista,entre 1933 e 1950; e pelo retorno de seus fundadores à Alemanha, no pós-guerra, entre 1950 e 1970. Atualmente, vive uma fase de construção de gerações posteriores aos seus fundadores (39).

Cabe destacar quea Teoria Crítica não se caracteriza por uma única abordagem. Na verdade, ela é composta de perspectivas diferenciadas de acordo com a modelo teórico que cada adepto da teoria desenvolveu. Por isso, a "Escola de Frankfurt" não se institui como escola, no sentido literal da palavra. Entretanto, as várias possibilidades teóricas ligadas pela Teoria Crítica têm como elo o olhar emancipatório e de rompimento com modelos de dominação colocados.

Inicialmente, com Walter Benjamim, os estudos abarcaramtemas da filosofia e da história, bem como temas relacionados à violência, inclusive as violações decorrentes do Estado (40). Max Horkheimer esteve em maior destaque nos estudos que questionavam a produção científica e filosófica, refletindo sobre a razão e as 
diversas dimensões de domínio do modelo capitalista. Em conjunto com Adorno, Horkheimer escreveu uma das principais obras da teoria, que é centrada na lógica de dominação da razão moderna e se caracteriza pelo distanciamento entre sujeito e objeto a partir de um modelo dominante em relação ao dominado (41).

Marcuse (42)voltou-se ao estudo das contradições internas entre as forças produtivas e as relações sociais, mostrando como a racionalidade tecnológica e científica modificou as bandeiras de classes para extinguir qualquer ameaça de revolução por parte dos trabalhadores. Por isso, ele defendia a emancipação por grupos sociais externos ao sistema produtivo.Claramente, conseguiu demonstrar que a teoria tradicional, afastada da moralidade e em conjunto com a racionalidade instrumental, formou uma grande modelagem tecno-científica-industrial. Com efeito,a indústria e a universidade se uniam para produzir conhecimentos e tecnologias que fossem consumidas pelo mercado.

Um dos críticos mais severos internamente à Teria Critica, Habermas defendia que a emancipação seria possível a partir da reforma do Estado Democrático de Direito (43), isto é, a partir da construção de espaços de diálogo que não fossem baseados na racionalidade instrumental. Esta não considera o pensar nem a objetificação do pensar a serviço da dominação, mas, sim, por meio da racionalidade comunicativa, baseada na linguagem, possibilitando a comunicação dialógica até mesmo em espaços públicos(44).

Foi com Jurguen Habermas e a Teoria do Agir Comunicativo que se tornou possível pensar a emancipação social a partir da produção de conhecimentos que impliquem a redefinição de redes de influências, enfraqueçam grupos de poder e estabeleçam outras formas de regulação do Estado. É o caso, por exemplo, da constituição de espaços de discussão que consigam neutralizar a racionalidade instrumental e a transformar em uma racionalidade comunicativa.

$\mathrm{Na}$ proposta de Habermas, a institucionalização de espaços democráticosinternos à estrutura jurídico-democrática poderia ser uma forma de os grupos sociais conduzirem a uma mudança de postura do Estado (16). Com isso, faz sentido pensar que as políticas e programas públicos precisam alinhar-se a uma racionalidade comunicativa, reconhecendo os grupos sociais demandantes de direitos a partir da discussão apropriada por eles, de modo a tomar ações efetivas enquanto Estado e de acordo com o interesse demandado. 
Entretanto, claro está que a inserção dos grupos nestes espaços democráticos ainda carece de ser potencializada, incentivada e promovida como parte intrínseca da mudança. Principalmente quando nos deparamos com questões essencialmente morais e culturais, como é o caso dos povos indígenas. As denúncias das mulheres indígenas sobre a violência têm sido frequentes, mas pouco se escuta as vozes dessas mulheres nos espaços democráticos e nem as decisões aí tomadas parecem contemplar asopiniões e a moral delas.

Ressalte-se que essa posição teórica tende a entrar em conflito com os Estudos de Colonialidade(16). Estes não acreditam numa emancipação no contexto da modernidade,uma vez que ela é a sustentação do sistema hierarquizado, de lugares e papéis sociais alinhados com o padrão de dominação imposto (45).

A tendência acima mencionada foidivisada por Lorenzo (16), que orienta outros estudos a aprofundarem essa relação, a fim de construir uma base teórica para a Bioética Crítica que contemple tanto a Teoria Critica como os Estudos sobre Colonialidade. No entanto, embora Habermas identifique um lado da modernidade que outros autores da Teoria Crítica não apontaram, como a possibilidade de diálogo por dentro do Estado, ou seja, por dentro da Modernidade, é importante destacar que não podemos, principalmente aqui na América Latina, desconsiderar elementos apontados pelos Estudos de Colonialidade que nos colocam em um lugar diferenciado, hierarquizado e subjugado a essa modernidade.

Além da relação de poder estabelecida, não podemos desprezar o conteúdo racial não abordado pela Teoria Critica, o qual tem sido considerado categoria essencial (45) para um pensar emancipatório e descolonial.Trata-se de uma manobra para classificar raças e hierarquizá-las entre os povos, buscando comprovações biológicas de inferioridade para sustentar o projeto de exploração e de hierarquização dos povos,que é característico da modernidade e que leva à Colonialidade da Vida. Como afirmamNascimento e Garrafa (46), esta:

[...]é exatamente o processo de criar uma ontologia da vida que autorize pensar que algumas vidas são mais importantes do que outras, desdeo ponto de vista político, fundando assim uma hierarquia e uma justificativa para dominação,exploração e submissão, sob o pretexto de ser esse um caminho para o desenvolvimento da vida menos desenvolvida.(p.292)

É no sentido de colonialidade de vida, assim caracterizado, que Nascimento e Garrafa denunciam que os indígenas e os africanos foram asvidas escolhidas para a 
opressão, em favor do progresso da Europa como projeto de desenvolvimento mundial. Nessa mesma linha, e aprofundando nosso objeto de estudo,faz-se necessário afunilar a análise para entender não só gravidade do problema que as mulheres indígenas vítimas de violência de gênero se colocam, mas também para entender como a modernidade atua no sentido de agravar esse problema.

Ao mesmo tempo queessa influência moderno/colonial impõe uma relação de poder do Norte para com o Sul, institui hierarquias na produção de conhecimento em que o Norte sempre tem o bastão do saber. Isso se forma a partir de relações de poder econômico,que impõem aos países padrões descontextualizados de desenvolvimento econômico, cultural e político. Dessa forma, tais países são levados pelas mãos do Estado a transformar sua estrutura cultural em marcas de marginalização e violência.

Nesse contexto, imagine-se o que pode ocorrer com as mulheres indígenas que vivenciam cultura diversa da modernidade e estão sujeitas a todas as violências consequentes da relação mundo moderno/colonial! É por isso que Segato (25) afirma que, assim como a raça, o gênero é categoria central para a crítica descolonial, transformado o papel e o corpo das mulheres em extensão do território de disputa edomínio de inimigos.

Portanto, a Teoria Crítica reflete muitos elementos de análise da influência hierárquica colonial e da possibilidade de propor espaços de discussão e emancipação característicos da Bioética Crítica.

\subsection{Estudos sobre Colonialidade: Colonialidade do Poder e do Saber}

Entender a Colonialidade é essencial para entender as mutações e transformações da ordem mundial vivida na atualidade moderna. Alguns estudiosos vêm desenhando linha crítica de argumentação que tem como foco a modernidade, partindo do princípio que ela se constitui a partir de uma lógica colonialsão estes estudiosos representados por AnibalQuijano, Walter Mignolo e Enrique Dussel, que fundamentam os chamados Estudos sobre a Colonialidade, todos da América Latina. Esses estudos buscam entender de quais maneiras as relações de poder, de conhecimento, de vida e de resistência têm se organizado em torno do grande ideal de dominação da modernidade(47). Isso é relevante para entender que pode existir 
uma organização de mundo baseada na hierarquização e colonização, ou melhor, no domínio de grupos menores com a injunção de vontades e prioridades de um eixo superior de dominação. Ou como designam os estudos sobe colonialidade, um modo "Eurocentrado de Interpretação".

Dentre as relações apontadas, a relação de poder é a que parece determinar a estrutura colonial na qual tudo aquilo que não tem a marca da modernidade passa a ser rechaçado e subjugado. Isso implicauma hierarquização centrada em quem detém a imagem do poder.Segundo Nascimento e Garrafa (46);

\begin{abstract}
Essa imagem supõe (e institui) um escalonamento hierárquico entre quem é desenvolvido e quem não é, de modo que essa hierarquização está pensada em termos de quem é moderno e quem não é. Há uma quase natural afirmação da inferioridade de quem não é marcado pela modernidade, precisando este ser educado, civilizado, colocado na marcha do progresso (pelos já modernos/desenvolvidos), mesmo que isso implique - e é o que geralmente acontece e serve aos interesses da presente discussão e crítica - na instauração de um processo de dominação.(p. 290)
\end{abstract}

Para Walter Mignolo (48), falar da perspectiva da Colonialidade do Poder é dizer queexistem mutações que influenciam as relações mundiais. Dessa forma é possível construir caminhos para o pensar descolonial e renunciar a todas as formas de imposição edificando novas formas de diálogo entre povos e culturas que interajam e troquem suas experiências, suas histórias e suas culturas.

Essa libertação ou emancipação se torna necessária a partir do questionamento sobre os efeitos da dominação do poder colonial. Estes se dão a partir de uma hegemonia global, por meio do exercício do poder e do saber sobre o outro, de modo que o poder colonial, especialmente na Europa, por todo seu império econômico e científico, prega ideias de desenvolvimento que atribuem a imperatividade de padrões econômicos, políticos, morais e epistemológicos hierarquizados, nos quais o superior é sempre identificado como superdesenvolvido e objeto de idealização de todos os outros.

Nas páginas preliminares ao livro intitulado Textos de Fundação de Anibal Quijano (48), Segato avalia que, partindo para um panorama continental, a colonialidade na mérica Latina ainda se faz presente na atualidade pelos consequentesproblemas sociais, como desigualdade, racismo e violência, que representam as diversas formas de vulneração do ser humano.

Os mecanismos de ação da Colonialidade são focais nas populações de baixo desenvolvimento social e econômico. Além desse campo, atingem também as 
subjetividades, como valores, saberes, línguas, símbolos e experiências das comunidades. A ação desses instrumentos se reflete na memória histórica dos povos, tendo eles que se submeter a uma transformação de padrões culturais e de formas de saber e agir, para se adequar ao padrão eurocentrado. Foram reduzidos e aprisionados para serem controlados pelo poder e explorados no trabalho. Essa transformação foi também capaz de alterar o imaginário dos povos, de tal modo que ainda nos dias atuais é perceptível a valorização de padrões europeus como verdades absolutas (48).

Considerando a capacidade de exploração, a expressão de um modo colonizado parece se refletir na imposição de padrões nos campos de produção de conhecimento, nas perspectivas, nos sistemas de imagens, nos símbolos, nos modos de significação, nos recursos e instrumentos de expressão, no intelectual e no visual. Como designa Quijano (48), trata-se deuma "alienação histórica" na qual o modo de fazer é marcado pelo encanto de participar do grupo dominador e de alcançar os mesmos benefícios materiais, o mesmo poder e a mesma natureza. Tudo isso em nome do "desenvolvimento".

O retrato da colonização na América Latina é desalentador, segundo Quijano. Isso porque, além de todas as formas de transformação impostas pelo poder dominador, foram ainda comprometidas as populações indígenas, que sofreram grande extermínio nos últimos tempos. Não só suas mortes, mas a morte de suas culturas são expressões formais que seguem padrões culturais europeus, alijando culturas a uma existência oral e iletrada.

Um dos elementos de estudo de Quijano é a questão da produção de conhecimento como paradigma da colonialidade cultural e da modernidaderacionalidade em que o pensamento europeu, propositadamente, estrutura a produção do conhecimento a partir de uma lógica objetiva e racional. Nessa lógica, o sujeito deixa de ser visto como possuidor de subjetividades para ter uma relação individualista de objeto. Desprezam-se, assim, a intersubjetividade e a totalidade social, que são fontes da produção do conhecimento para o autor.

Essa relação do sujeito enquanto objeto que despreza a existência do outro e remete a um pensamento isolado e de propriedade que favorece a colonialidade. Nessa linha, também está a motivação para ações violentas. É o que Nascimento e Garrafa confirmam, quando dizem que "A colonialidade da vida normalmente tem 
sido usada como pretexto para práticas violentas contra sociedades"(46). Mas violentas, em especial, para as mulheres, que historicamente têm tido seus corpos usados como instrumentos de guerrae para demonstração de domínio de território alheio ou de força punitiva(7).

O questionamento "Qué papel tienen las relaciones de género en este proceso?', feito por Segato(25),é central para entender o problema da violência contra a mulher. É perceptível que a crueldade e o desamparo a mulheres vítimas de violência aumentam conforme a modernidade e o mercado avançam. Até por que os protagonistasdesse espaço são representados pelo poder masculino e pelos interesses de hierarquização para a conquista do projeto colonial.

A forma de agir do Estado, embora disfarçada na defesa da coisa pública, se transforma em duro ataque às formas alternativas de organização social. Ele invade e cerceia os espaços de autonomia e práticas comunitárias pela necessidade do controle. A manobra se dá a partir de uma concepção de igualdade disfarçada em concepção de modernidade com fundo liberal e capitalista, mas carregada de males como o racismo e a hierarquização (25). Assim, o Estado dificilmente pode escolher entre a proteção às autonomias e direitos comunitários e o exercício do controle e a manutenção do seu domínio. Nesse contexto, o papel do Estado seria então o de devolver a jurisdição e a garantia de deliberação aos povos para que eles possam dispor de seu próprio projeto histórico e, assim, promover a interculturalidade.

Para Segato (25), a defesa das autonomias torna-se inviável a partir do relativismo cultural e é preciso reconhecer o pluralismo histórico de modo substitutivo ao relativismo cultural. O reconhecimento da pluralidade, da autonomia para deliberações e da troca de experiências de outros povos leva à construção da interculturalidade acrescida do elemento histórico indispensável para tal processo. Isso significa promover uma comunicação entre os povos, olhando para as marcas deles na história.

\subsection{Interculturalidade e Direitos humanos}

O exercício de reconhecimento da pluralidade perpassa a interculturalidade como um elemento importante no estabelecimento de laços entre as vivências do passado e a construção do futuro. E nessa construção decorrem experiências 
conflitantes como trocas de interesses, antagonismos, conflitos éticos e posturas políticas e que fazem parte de uma história.

Para ampliar a base teórica da bioética crítica, conduzindo-a a uma reflexão adequadamente cultural, a interculturalidade será outro braço de aplicação dabioética no âmbito da questão da mulher indígena.

A interculturalidade é a relação de diálogo estabelecida entre atores de culturas diferentes, buscando entender a forma de organização das sociedades. Segundo o Consejo Regional Indígena de Cauca(49), assim entendida, a interculturalidade "É um projeto político, que transcende o educativo para pensar na construção de sociedades diferentes [...] noutro ordenamento social".

Nesse sentido, tem sido abordado de três perspectivas distintas, segundo Walsh (49). A primeira é a perspectiva relacional, que faz referência à forma mais básica e geral de contato e intercâmbio entre culturas, que se dá por igualdades ou desigualdades nas relações estabelecidas entre culturas como as indígenas e afrodescendentes. A segunda é perspectiva funcional, que busca promover o diálogo, a convivência e a tolerância, visando a inserção na estrutura social já existente, sem questionar as causas de diferenças. Por isso, é vista como uma nova forma de dominação, objetivada apenas no controle do conflito ético e na manutenção da estabilidade social, como uma estrutura de ilusão que tem como único objetivo o projeto neoliberal. A terceira e última é a perspectiva crítica, que parte do problema estrutural-colonial-racial para se contraporao campo funcional, induzindo a uma discussão sobre a transformação das estruturas e relações sociais de forma distinta, a partir do "reconhecimento de que a diferença se constrói dentro de uma estrutura e matriz colonial de poder racializado e hierarquizado, com os brancos e 'branqueados' em cima e os povos indígenas e afrodescendentes nos andares inferiores".

No campo dos Direitos Humanos, além das convenções já enunciadas como normativas positivadas como bastões de proteção, a atenção deve ser dirigida a uma visão indutora de olhares éticos. Isso porque, segundo Segato, faz-se necessário introduzir um outro princípio de justiça, afastado da moral e da lei, que não esteja calçado em normas positivas e enumeráveis(50).

Esse princípio, segundo ela, seria a pulsão ética que "nos possibilita não somente contestar e modificar as leis que regulam o "contrato" impositivo em que se 
funda a nação, mas também distanciarmo-nos do leito cultural que nos viu nascer e transformar os costumes das comunidades morais que de fazemos parte".

Nesta pulsão ética, a Bioética tem se aproximado dos direitos humanos pela defesa da dignidade humana, fazendo interlocução com valores morais. Nesse contexto, a dignidade humana "é o mais evidente ponto de aproximação entre a Bioética e os Direitos Humanos, sendo o princípio fundamental e alicerce de toda construção teórica nos dois campos do saber" (51).

Abioética interculturalsurge da necessidade de se ter uma ferramenta que seja capaz de considerar asnuances da questão da violência de gênero, considerando os elementos éticos e morais que asseverem a proteção da dignidade das mulheres. Dessa forma, a Bioética Intercultural se torna essencial para solucionar questões que exigem o cuidado e a contextualização cultural. É por isso que, seguindo ferramenta sugerida por Oliveira (52), vamos ampliar esse entendimento e o levar para o campo da saúde epara o campo das políticas e programas públicos instituídos. Assim procedendo, busca-se seguir as premissasapresentadas pela autora de que não se devem analisar culturas a partir de padrões próprios, mas buscar sempre o encontro da igualdade entre as culturas e promover visão crítica para enfrentar alguns de seus elementos.

Com o valor ético de ser a verdadeira cultura da humanidade,percebe-se ligação entre os direitos humanos e a bioética intercultural. Esta apresenta-se sob a forma de espaço capaz de oferecer olhares éticos, morais, políticos e culturais para atomada de decisão e o fornecimento de procedimentos de mediação necessáriosao enfrentamento de questões relacionadas aos povos indígenas.

É interessante desenhar, a partir da interculturalidade,o papel descritivo e não normativo que a bioética assume ao estudar e descrever os conflitos culturais a partir dos comportamentos morais e das suas diferenças. Ao considerar tais particulares, a bioética contribui para o entendimento dos direitos humanos como interculturalismo com igualdade de valor para as culturas(52).

Entretanto, a igualdade não pressupõe a ausência de conflitos entre as culturas, pois o conflito bioético está calcado na divergência moral. No caso em estudo, tal conflito está relacionado com a necessidade moral de proteção das mulheres indígenas e com a efetivação de políticas institucionais direcionadas, que 
não apenas descrevam formas de atuação adequada, mas permitam a construção do processo com autonomia e protagonismo.

Como descreve a Declaração Universal sobre Bioética e Direitos Humanos em seu artigo 12, do Respeito pela Diversidade Cultural e pelo Pluralismo (53):

\begin{abstract}
A importância da diversidade cultural e do pluralismo deve receber a devida consideração. Todavia, tais considerações não devem ser invocadas para violar a dignidade humana, os direitos humanos $e$ as liberdades fundamentais nem os princípios dispostos nesta Declaração, ou para limitar seu escopo.
\end{abstract}

Os direitos humanos são fundamentais para a proteção dos indivíduos de grupos minoritários, pois servem de defesa contra a inserção de outras culturas, inclusive as impostas pelo Estado. Assim, essa limitação deve se estender aos atos de omissão sobre um problema tão negligenciado como a violência contra mulheres indígenas. Isso significa estabelecer diálogo intercultural sem violar a dignidade humana, mesmo com a supremacia hierarquizada do Estado ou entre culturas diferentes umas das outras.

Assim Oliveira (52) afirma que:

\begin{abstract}
Determinadas práticas danosas a mulheres e crianças, como casamentos precoces, estupros coletivos como forma de justiça entre comunidades e homicídios de mulheres em nome da honra, não devem ser toleradas sob o manto de serem práticas culturais. Até porque certas práticas culturais são reflexos de patriarcalismo, relações assimétricas de poder, discriminação de mulheres e subjugação de crianças.(p. 85)
\end{abstract}

A base de direitos humanos sustenta a proteção construtiva de uma cultura de humanidade, capaz de exigir dos governos nacionais e dos organismos internacionais ações reais e de efeito. Limitações que aparecem nessas discussões são sempre acobertadas pela justificativa das práticas culturais como práticas específicas a cada cultura.

\title{
4.6 Feminismo
}

Falar sobre gênero é necessário para trazer ao presente trabalho elementos dos estudos sobre o feminismo e as bandeiras de luta das mulheres, afim de melhor compreender o lugar histórico dos papéis femininos na sociedade.

$\mathrm{Na}$ bioética, a questão feminina inicialmente foi tratada pelo aspecto da medicalização e regulação do corpo no âmbito reprodutivo (54), avaliando apenas questões de pesquisas sobre o sistema reprodutivo. Mais adiante é que passou a 
avaliar a mulher do ponto de vista da autonomia e do direito a decidir sobre o seu próprio corpo. Diniz (55) cita,a partir de Wolf,como pontos críticos da bioética

\begin{abstract}
em primeiro lugar, uma crítica aos pressupostos da teoria principialista que se supõem universalizáveis; em segundo, apontam para os limites da ideologia liberal que tem o individualismo e, consequentemente, o princípio da autonomia como valor máximo; em terceiro, e para nós, talvez, a crítica mais importante, reconhecem que a estrutura da bioética preserva os interesses dos que se encontram em vantagem social, constituindo uma 'bioética para os privilegiados(p. 04)
\end{abstract}

Wolf (56)vai além na afirmativa de que a bioética, inclusive no campo acadêmico, tem tido interesse seletivo quanto a estudos relacionados à medicina e à ciência, Isso se traduz em um isolamento das questões feministas e, conforme já apontado,em umaColonialidade de saber que negligencia questões femininas como a violência de gênero.

Atualmente, afirma Diniz, as pautas da abordagem feminista da bioética foram se ampliando e hoje caminham em direção à desconstrução da estrutura hegemônica das instituições e das práticas médicas sobre o corpo feminino. Há inclusive discussões sobre pesquisa clínica com mulheres, sobre o uso da objeção de consciência geralmente relacionados com as mulheres e suas decisões reprodutivas e sobre o envelhecimento do corpo feminino. Isso prova que a bioética tem sido campo rico e ampliado de análise das questões femininas (57).

Entretanto,Segato (25) apresenta algumas visões diferenciadas sobrequestão de gênero, principalmente a respeito dos modelos de pensamentos feministas. O primeiro modelo apresentado pela autora é o feminismo eurocêntrico, que considera que o problema da dominação de gênero é patriarcal e universal, justificando a possibilidade de transferência dos avanços da modernidade às mulheres não-brancas, indígenas e negras colonizadas. Assim, tal modelo impõe uma superioridade moral que reduz aquelas mulheres à desigualdade $\mathrm{e}$ a discriminação.

Já o segundo modelo de pensamento feminista afirma que a questão de gênero inexistia no mundo pré-colonial. E o terceiro, defendido pela autora, considera a possibilidade de existência de nomenclaturas de gênero nas sociedades tribais e afro-americanas, caracterizando uma organização patriarcal de baixa intensidade que não se submete a lideranças do feminismo eurocentrado.

Por isso, reconhecer a questão de gênero como central na discussão parece abre um caminho de possibilidades para conflitos violentos nos quais as mulheres 
são tão vitimizadas. Principalmente por entender que o corpo feminino lhes pertence e que não cabe a ninguém inscrever marcas nele, exceto a própria mulher. A elacabe dizer o lugar para o qual deseja ir e o papel que deseja assumir, de modo adequado à sua realidade, sem hierarquias de poder, de saber ou culturais propostas pelos discursos europeus e colonizadores.

Diante desse posicionamento, e a partir do referencial teórico da Bioética Critica, dos Estudos de Colonialidade, da Interculturalidade, dos Direitos Humanos e do Feminismo, elementos que cercam a temática apresentada neste trabalho, entendemos que a Bioética seja sede para a discussão e reflexão do problema da violência de gênero contra a mulher indígena. De acordo com Lorenzo, entendemos também que isso é "bastante útil à fundamentação teórica do componente analítico da ética aplicada, (...) e especificamente na análise dos conflitos e desvios éticos em torno das ciências da vida - tarefa própria da bioética"(16).

Com esse compromisso, propomos a análise da invisibilidade científica e das negligências institucionais sobre a violência contra a mulher indígena com base na Bioética Crítica. A ideia é aprofundar o estado da arte a partir do entendimento sobre as produções no campo ético, cientifico e institucional e sobre o comportamento dessa rede diante do contexto intercultural. 


\section{METODOLOGIA}

Trata-se de uma revisão integrativa que consiste em um método de avaliação específico e que é normalmente utilizado para pesquisas de literatura sejam empíricas ou teóricas mas que forneçam uma compreensão ampla de um fenômeno singular ou um problema de saúde conforme sintetiza Broome (58). Conforme proposto por Whittemore e Knalf (59) consiste em método que inclua pesquisas experimentais e não experimentais e que permite uma combinação de dados teóricos com literatura para definição de conceitos, revisão de teorias, analise de provas e de metodologia entre outras possibilidades. Quando bem elaboradas ela é capaz de contribuir para o desenvolvimento das teorias científicas, na pratica e nas políticas públicas de saúde.

Desse modo, a revisão aqui proposta é constituída por meio de levantamento dos artigos científicos publicados entre os anos 2000 e 2015.A revisão constou de dois corpi de documentos: 1. artigos científicos selecionados nas bases de dados da Scientific Eletronic Library Online (Scielo) e da Literatura LatinoAmericana e do Caribe em Ciências da Saúde (LILACS); e 2. Portarias, políticas públicas e programas estabelecendo diretrizes para organização da atenção à saúde da mulher e saúde indígena e para o enfrentamento à violência de gênero. A busca desses dados foi realizada entre os meses de setembro e dezembro de 2015.

Para a pesquisa dos artigos, foram utilizados os descritores em Ciências da Saúde (DECS) "violência contra a mulher", "violência de gênero" e bioética", de forma separada e também em combinação com os descritores: "população indígena", "povos indígenas" e "indígenas", utilizando-se o operador boleanoand. Os critérios de inclusão foram: 1. artigos publicados entre 2000 e 2015; 2. artigos publicados em periódicos brasileiros. Os critérios de exclusão foram: a) artigos que não se remetessem ao contexto brasileiro; b) artigos dirigidos a um grupo social específico de mulheres, como grupos de trabalhadoras, entre outros; c) artigos abordando uma região ou circunstância específica onde não há possibilidade de relação com a questão indígena; d) artigos cujo tema principal fosse outras formas de violência doméstica, tais como em crianças e idosos. Para análise do corpus final de artigos, foi desenvolvido um instrumento composto dos seguintes tópicos: título 
do artigo, autores, ano de publicação, objetivo, citação ou abordagem dada à questão da mulher indígena. Os resultados encontram-se sintetizados nosQuadros1 e 2 .

Os documentos legais ou político-institucionais foram definidos por conveniência, elegendo-se aqueles que regulamentam tanto ações de proteção contra a violência de gênero quanto políticas públicas e ações programáticas relacionadas à saúde da mulher ou à saúde indígena. O resultado da análise desses documentos é apresentado no Quadro 3. 


\section{RESULTADOS E DISCUSSÃO}

É importante destacar,logo de início, o fato de que, enquanto isolados, os descritores "violência contra a mulher" e "violência de gênero"encontraram570 artigos, enquanto apenas um artigo foi encontrado quando esses descritores foram cruzados através do operador boleano AND com os descritores "população indígena", "povos indígenas" e "indígenas". Após a aplicaçãodos critérios de inclusão e exclusão aos 570 artigos encontrados,chegou-se a um número final de 66 artigos, sobre os quais foi aplicado 0 instrumento de análise.Os principais achados relacionados à pesquisa estão sintetizados no Quadro 1.

\begin{tabular}{|c|c|c|}
\hline Variável & № & $\%$ \\
\hline \multicolumn{3}{|l|}{ Ano de publicação } \\
\hline 2006 a 2008 & 8 & 12,12 \\
\hline 2009 a 2011 & 20 & 30,30 \\
\hline 2012 a 2014 & 27 & 40,91 \\
\hline 2015 & 11 & 16,67 \\
\hline \multicolumn{3}{|l|}{ Categoria de Objetivos Principais dos Artigos } \\
\hline $\begin{array}{l}\text { 1. Articulação de serviços e planejamento da atenção à saúde } \\
\text { para a mulher vítima de violência } \\
(60,61,62,63,64,65,66,67,68)\end{array}$ & 9 & 13,64 \\
\hline $\begin{array}{l}\text { 2. Discussão sobre a condição de gênero enquanto categoria } \\
\text { do fenômeno da violência } \\
(69,70)\end{array}$ & 2 & 3,03 \\
\hline $\begin{array}{l}\text { 3. Enquadramento da violência de gênero no campo da saúde } \\
\text { pública/coletiva } \\
(71,72,73)\end{array}$ & 3 & 4,55 \\
\hline $\begin{array}{l}\text { 4. Estudo de articulações gênero/raça/cor/etnia na violência } \\
\text { contra a mulher } \\
(74,75)\end{array}$ & 2 & 3,03 \\
\hline $\begin{array}{l}\text { 5. Estudo de práticas discursivas sociais sobre gênero e } \\
\text { violência } \\
\text { (76) }\end{array}$ & 1 & 1,52 \\
\hline $\begin{array}{l}\text { 6. Estudo do funcionamento das redes institucionais de } \\
\text { proteção } \\
(77,78,79)\end{array}$ & 3 & 4,55 \\
\hline $\begin{array}{l}\text { 7. Estudos de prevalência de tipos de violência e mortalidade } \\
\text { resultante } \\
(80,81,82,83,84,85,86,87,88)\end{array}$ & 9 & 13,64 \\
\hline $\begin{array}{l}\text { 8. Estudos de relatos pessoais sobre formas de } \\
\text { enfrentamento à violência de gênero } \\
\text { (89) }\end{array}$ & 1 & 1,52 \\
\hline
\end{tabular}




\begin{tabular}{|l|r|r|}
\hline $\begin{array}{l}\text { 9. Estudos sobre a constituição de redes comunitárias de } \\
\text { apoio à mulher vítima de violência } \\
(90,91)\end{array}$ & 2 & 3,03 \\
\hline $\begin{array}{l}\text { 10. Estudos sobre o perfil das mulheres vítimas de violência } \\
\text { doméstica e ou de seus agressores } \\
(92,93,94)\end{array}$ & 3 & 4,55 \\
\hline $\begin{array}{l}\text { 11. Estudos sociológicos e ou jurídicos sobre a Lei Maria da } \\
\text { Penha } \\
(95,96,97)\end{array}$ & 25 & 37,88 \\
\hline $\begin{array}{l}\text { 12. Percepções e atitudes de profissionais da saúde diante da } \\
\text { violência } \\
(98,99,100,101,102,103,104,105,106,107,108,109,\end{array}$ \\
$\begin{array}{l}110,111,112,113,114,115,116,117,118,119,120,121, \\
122)\end{array}$ & 1 & 1,52 \\
\hline $\begin{array}{l}13 . \\
\text { Percepções e atitudes de profissionais dos campos jurídico } \\
\text { e policial } \\
(123)\end{array}$ & 2 & 3,03 \\
\hline $\begin{array}{l}\text { 14. Revisão de literatura sobre o tema } \\
(124,125)\end{array}$ & 3 \\
\hline
\end{tabular}

Quanto à presença ou menção à questão intercultural dos 66 artigossete mencionaram a questão intercultural ou relacionada à mulher indígena, sendo que três (4,5\%) abordaram a importância de considerar questões históricas, o respeito a diferentes relações sociais e ao pluralismo cultural e os outros quatro (6,5\%) artigos abordaram a necessidade de ampliar estudos para as populações indígenas e a necessidade de considerar as relações históricas e étnicas dos povos indígenas ao tratar do tema da violência de gênero.

Sobre o conteúdo ético ou especificamente sobre a incidência de bioética como campo de estudo da violência de gênero nos artigos, Bandeira(70) assume a necessidade da ética ser um dos alicerces para o desenvolvimento de políticas de atendimento e acompanhamento das mulheres em situação de violência. Ao contrário, Azevedo (95) já diz que o movimento contra a violência de gênero tem transferido ao "domínio público as turbulências, perplexidades e incertezas vividas na privacidade" conduzindo à uma desestabilização do Estado em termos de controle, domínio e poder. Assume ainda que as leis já cumprem aracionalidade ética necessária a uma conduta emancipatóriacomo forma de intervenção do Estado. Enquanto caminha-se para a construção de soluções eticamente adequadas, a racionalidade ainda conduz alguns autores a uma frieza e subjugamento da gravidade do problema da violência. Por outro lado a afirmação dele confirma que a luta de movimentos sociais e outros está alterando a forma de relação com o Estado. 
Já no contexto da LeiMaria da Penha o elemento ético é utilizado por Pougy (77) no sentido de que as instancias jurídicas devem considerar a ética em suas avaliações de condutas como certo ou errado e no tratamento do conflito vivido, aplicando a ética o papel de mediação de conflitos.

É de se esperar um estudo que trata da articulação entre gênero e raça na questão da violência, nos traga uma boa reflexão, em que nos sugere a inserção da ética para a reflexão e alteração das relações de dominação como em estudo de Silveira e Nardi (74):

Dessa forma, o que podemos fazer é trazer a ética para o campo das relações cotidianas que marcam a microfísica do poder, exercitando-a como prática reflexiva da liberdade e, dessa forma, alterando os jogos de poder para que obedeçam a relações de forças mais equânimes.(p. 324)

Nesse processo de reflexão é importante se considerar que a violência de gênero é um problema de perspectivas éticas e políticas de compreensão de formas de inibir a violência e do cuidado a saúde da mulher em busca emancipação, por isso, Guedes, Fonseca e Egry (62)' também sugerem que a Saúde Coletiva é espaço para estas discussões.

Há ainda discussões que são feitas a partir da visão do homem diante do fenômeno da violência contra a mulher, são apresentados argumentos que, de certo modo, demonstram a vitimização dos homens ao sistema machista e reprodutor de violências conforme descreve Medrado e Méllo (76)em seu artigo intitulado "Posicionamentos Críticos e Éticos sobre a Violência contra as Mulheres":

\footnotetext{
Em síntese, as informações acima evidenciam que os homens estão colocados no contexto da violência em diferentes lugares, inclusive muitas vezes como produto-alvo de padrões de subjetividade orientados por modelos de gênero e de relações hierárquicas de poder que definem a dominação masculina sobre as mulheres.(p. 81)
}

Já na perspectiva dos profissionais de saúde, a ética é percebida nos estudos como característica necessária ao bom desempenho do trabalho por estar relacionada a atuação interpessoal (64) e técnico (114) entre os profissionais e as mulheres atendidas.

Os achados com a presença da temática geralmente estão relacionados a reconhecer as diferenças étnicas ou interseccionadas com a questão de raça/cor no 
estudo de violência de gênero, como no artigo de D'Oliveira e Schraiber (73) em que:

Por outro lado, para a efetiva proteção dos direitos, é necessário o reconhecimento por todos dos eixos de desigualdade social, especialmente, no que tange às diversas manifestações das desigualdades de gênero, mas também de classe e raça/etnia.(p. 137)

Esses achados estão contidos do levantamento de categorias de objetivos sendo que apenas dois deles se remetem de forma específica à questão da mulher indígena reconhecendo-as como raça histórica vítima de violências e indicando a necessidade de novos estudos nesse campo. Nenhum dele se remete à bioética especificamente como campo de atuação, embora seja encontrado o sentido da responsabilidade ética como propõe Santos e Vieira (79) ao afirmar que a ética passsa ser uma elemento necessário ao desenvolvimento do trabalho em saúde, uma concepçãointerdisciplinar, que respeite as diferenças, que seja corresponsável propondo soluções compartilhadas com o objetivo de alcançar uma efetiva integralidade do cuidado à saúde das mulheres vítimas de violência.

Com relação ao ano de publicação, embora a pesquisa tenha sido prevista a partir do ano 2000, os resultados começaram a surgirem 2006, provavelmente influenciados pela promulgação da Lei Maria da Penha. Nota-se que os anos de 2012 a 2014 tiveram a maior concentração de produção de artigos relacionados ao tema, com cerca de $40 \%$ do total dos artigos achados produzidos nesse período. Em 2015 já são 11 artigos, sinalizando uma crescente na produção desde o ano de 2006.

Os estudos cujo objetivo principal foi analisar a percepção e atitudes de profissionais da saúde diante da violênciade gênero representaram 37\% do total da amostra, demonstrando acentuado interesse em que eles contribuam para programas de educação continuadacom vistas à prevenção da ocorrência de violência contra a mulher e ao atendimento àsvítimas. Eles são seguidos pelos estudos, em número de publicações, por artigos com objetivo de avaliar a articulação de serviços e planejamento da atenção à saúde para as mulheres vítimas de violência e em igual número por aqueles que estimama prevalência de tipos de violência e mortalidade resultante. Vale ressaltar que nesse contingente de categorias de objetivos que representa cerca de $65 \%$ do total de publicações, nenhumartigo nesse grupo se remete à questão da mulher indígena. Destaca-se que $65 \%$ é a proporção do total de estudos produzidos por dois estados da Federação, 
cujos índices de população indígena são diversos,São Paulo com 9.160 produz $36,3 \%$ das produções e o Rio Grande do Sul com 32.989 pessoas autodeclaradas indígenas produz $28,7 \%$.

Ao compararmos o retrato dos dez estados mais violentos para a mulher com contingente significativo de povos indígenas vemos que Roraima detém 49.637 indígenas autodeclarados e o maior índice $(15,3)$ de morte de mulheres no Brasil. No fim do ranking (1) em decimo lugar está o Estado do Pará com 39.081 indígenas e um índice de 5,8 mulheres mortas por questões de gênero nesse Estado. Interessante observar o estado de Mato Grosso do Sul com 61.737 (126), ecom maior parcela de povos indígenas entre os dez Estados não teve nenhum artigo registrado no levantamento aqui apresentado. Em nenhumas das situações e dados informados acima existe a produção científica voltada para a questão da violência de gênero contra as mulheres indígenas o que pode significar uma escassez de produção e uma rota de produção descontextualizada com as realidades locais.

O Quadro 2 apresenta a distribuição da produção por Região e Estado onde os estudos foram realizados.

\begin{tabular}{|c|c|c|c|}
\hline \multicolumn{2}{|c|}{ Quadro 2-Porcentagem de produção científica no tema por região e estados e categoria de } \\
objetivos
\end{tabular}


Surpreendentemente, a região com maior produção sobre o tema é a região sudeste em especial o Estado de São Paulo e não outras regiões que tenham maior contingente de povos indígenas. Ademais, a preocupação com a percepção dos trabalhadores da saúde é o tema de maior interesse dos pesquisadores o que pode demonstrar uma preocupação com a preparação da rede para receber mulheres vítimas de violência.

Chama atenção também a invisibilidade da mulher indígena em torno das questões de violência de gênero,mesmo em estudos com maior número de sujeitos, como os inquéritos ou revisões documentais de maior porte. O estudo que caracterizou 2.674 mulheres em São Paulo vítimas de violência por parceiro íntimo (66) não encontrou nenhuma mulher indígena. O mesmo ocorrendo com o que estudou 939 fichas de notificação entre os anos de 2006 e 2008(85)em Fortaleza/CE que não encontrou nenhumaocorrência relacionada à mulher indígena. Outroestudo envolvendo 56 serviços na região metropolitana de São Paulo no qual foram entrevistados 100 profissionais gerentes e técnicos sobre a inserção dos psicólogosna rede de assistência à mulher (64)não registrou qualquer preocupação por parte dos entrevistados sobre dificuldades com realidades culturalmente diversas ou especificamente relacionadas à mulher indígena. No mesmo sentido, um amplo estudo envolvendo221 médicos e enfermeiros sobre o atendimento de mulheres em situação de violência em Ribeirão Preto/SP também não teve referência a mulheres indígenas(102). Obviamente esses achados podem ser decorrentes unicamente de campos de pesquisa com baixa proporção da população indígena, mas é lícito que levantem também a suspeita do não reconhecimento pelas mulheres indígenas da efetividade das redes oficiais de proteção ou da existência de barreiras simbólicas ou funcionais de acesso.

Se confrontarmos os resultados da presente revisão com o fato de que a violência contra a mulher tem sido considerada um problema de dimensões globais (127) e, no Brasil, descrito como um problema prioritário para a saúde pública,(128, 129)e que,por isso mesmo, passou a ganhar um relevante espaço de discussão no campo científico e na formulação de políticas públicas, veremos claramente que a negligência científica em relação à violência específica contra a mulher indígena e quanto aos aspectos culturais necessários para lidar com o problema não sãoquestões emergentes, mas estruturadas por uma produção colonial de saber. 
Chamamos de "colonialidade do saber" a forma característicada produção do conhecimento hegemônico, fortemente restringido por uma visão de mundo construída pela modernidade europeia, a quallegitima o conhecimento válido a partir de uma relação de identidade de valores estéticos, políticos e morais com os padrões coloniais dominantes, e onde a identidade de raça é estruturante (130).

Nesse sentido, a atitude colonial integrada às próprias subjetividades de gestores, profissionais de saúde e pesquisadores provoca uma invisibilidade das mulheres indígenas, o que afeta tanto o nível da prática assistencial nos planos jurídicose de saúde quanto o próprio interesse científico em abordar o problema.As mulheres indígenas são, assim,subtraídas do direito de falar de suas próprias histórias em favor de discursos hegemônicos, mesmo quando tratamos de discursos que lutam contra outras formas de dominação. Hagreaves (10) demonstra bem isso ao tratar das narrativas nos discursos feministas antiviolência.

O mais grave é que esse silêncio e invisibilidade ocorrem de forma concomitante ao contínuo processo de transformação dos atributos e tarefas culturais de gênero, em função do contato com não indígenas, que irão redefinirprestígio e reconhecimento de homens e mulheres na comunidade, fator que por si só é potencialmente conflitivo (14).Surgemtambém novos padrões comportamentais, incluindo, em especial, o alcoolismo, identificado pelas mulheres indígenas como o principal fator potencializador da violência de gênero.

Tovar-Restrepo e Irazábal (15) demonstram que a situação começa a envolver todo o espaço de convivência da mulher indígena. No âmbito doméstico, são sujeitas da mudança de comportamento dos homens para o agir masculino ocidental e violento e fora de suas casas são vitimadas pela violência consequente da relação social com os não índios, e, o mais grave é que, em muitas situações, a violência parte de atores das redes oferecidas pelo Estado que deveriam oferecer proteção e apoio, a exemplode militares em torno de suas terras. Kuokkane (9) afirma que em todo mundo a violência contra a mulher indígena tem sido agravada pelo fenômeno da globalização, que passa a influenciar a economia e as formas de vida cotidianas, atacando-as em sua capacidade de autodeterminação.

Percebe-se pela revisão apresentada neste trabalho a existência de uma intencionalidade científica de estudos e registros que não são representadas pela neutralidade da ciência. O que se percebe é o direcionamento de estudos alinhados 
a uma colonialidade de saber. Ou seja, o problema da violência de gênero contra a mulher indígena existe, vem sendo denunciado, mas não está descrito nos estudos científicos como objetivos principais.A prevalência dos estudos aqui apresentados são no sentido de analisar as formas de Articulação dos serviços e planejamento da atenção, entretanto a partir da perspectiva do Estado e não do sujeito, o que representa a imposição de produção de conhecimento direcionada ao centro, e por isso não neutra desconsiderando a subjetividade do sujeito e o torna objeto de análise.

Se, por um lado, a violência contra a mulher indígena tem sido negligenciada pela produção científica nacional, a participação de movimentos sociais e associações civis de mulheres indígenas e a atuação de alguns antropólogos e sanitaristas sensíveis à questão conseguiram pautar o problema em algumas políticas públicas e programas governamentais.

O Quadro 3sintetiza os resultados da revisão das principais políticas e programas relacionados.

Quadro 3. Políticas e Programas relacionados à saúde indígena, saúde da mulher e violência de gênero, quanto àpresença ou não de abordagem específica da

\begin{tabular}{|c|c|c|c|}
\hline $\begin{array}{l}\text { Título do } \\
\text { documento }\end{array}$ & Ano & Instituição & $\begin{array}{c}\text { Presença de abordagem à } \\
\text { questão de violência de } \\
\text { gênero no contexto } \\
\text { indígena }\end{array}$ \\
\hline $\begin{array}{c}\text { Portaria no } 254 \\
\text { Aprova a } \\
\text { Política } \\
\text { Nacional de } \\
\text { Atenção à } \\
\text { Saúde dos } \\
\text { Povos } \\
\text { Indígenas } \\
\text { (PNASPI) }\end{array}$ & 2002 & Ministério da Saúde & $\begin{array}{l}\text { Diretriz } 4 \text { "acompanhamento, } \\
\text { monitoramento e } \\
\text { desenvolvimento de ações } \\
\text { que venham coibir agravos } \\
\text { de violência (suicídios, } \\
\text { agressões e homicídios, } \\
\text { alcoolismo) em decorrência } \\
\text { da precariedade } \\
\text { dascondições de vida e da } \\
\text { expropriação e intrusão das } \\
\text { terras indígenas;" (p.19) } \\
\text { Não se refere } \\
\text { especificamente a ações ou } \\
\text { mecanismos dirigidos à } \\
\text { proteção contra a violência } \\
\text { de gênero. }\end{array}$ \\
\hline $\begin{array}{l}\text { Princípios e } \\
\text { Diretrizes da } \\
\text { Política } \\
\text { Nacional de }\end{array}$ & 2004 & Ministério da Saúde & $\begin{array}{l}\text { Faz menção ao contexto do } \\
\text { etnodesenvolvimento das } \\
\text { sociedades indígenas e da } \\
\text { atenção integral à mulher }\end{array}$ \\
\hline
\end{tabular}




\begin{tabular}{|c|c|c|c|}
\hline $\begin{array}{l}\text { Atenção } \\
\text { Integral à } \\
\text { Saúde da } \\
\text { Mulher } \\
\text { (PNASM) }\end{array}$ & & & $\begin{array}{l}\text { indígena (p. 53).Não aborda } \\
\text { especificamente a violência } \\
\text { de gênero neste contexto. }\end{array}$ \\
\hline $\begin{array}{c}\text { Pacto Nacional } \\
\text { de } \\
\text { enfrentamento } \\
\text { à Violência } \\
\text { Contra as } \\
\text { Mulheres } \\
\text { (PNEVCM) }\end{array}$ & 2011 & $\begin{array}{l}\text { Secretaria de Política } \\
\text { para Mulheres da } \\
\text { Presidência da } \\
\text { República (SPM/PR) }\end{array}$ & 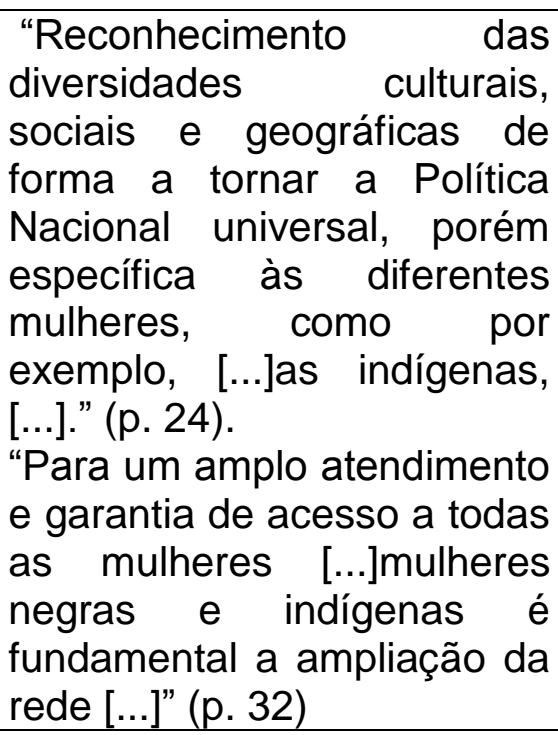 \\
\hline $\begin{array}{c}\text { Plano Nacional } \\
\text { de Políticas } \\
\text { para as } \\
\text { Mulheres } \\
\text { (PNPM) }\end{array}$ & 2013 & $\begin{array}{l}\text { Secretaria de Política } \\
\text { para Mulheres da } \\
\text { Presidência da } \\
\text { República (SPM/PR) }\end{array}$ & $\begin{array}{l}\text { O Plano traz em seu capítulo } \\
7 \text { - instituição de fóruns de } \\
\text { Mulheres Indígenas para a } \\
\text { definição de estratégias de } \\
\text { enfrentamento à violência } \\
\text { contra a mulher indígena. (p. } \\
\text { 71). }\end{array}$ \\
\hline
\end{tabular}


Como podemos notar, a maior e mais importante política direcionada à saúde indígena,(131) que cria um subsistema específico de saúde e enuncia diretrizes para a organização da atenção em todo o território brasileiro, apesar de proporestratégiaspara enfrentamento das práticas de violência em geral, não cita a violência de gênero como uma situação específica que demande ações também específicas. O mesmo ocorre com a PNASM,(132) que, embora chame a atenção às particularidades para a atenção em saúde das mulheres indígenas e de outros grupos de mulheres com identidades culturais diversas e reconheça a escassez de dados epidemiológicos produzidos sobre o grupo, não se remete especificamente à violência de gênero em nenhuma parte de seu texto.

Cabe observar que embora o Estado detenha políticas para as situações apresentadas, e ainda que os estudos predominantes nas regiões estejam relacionados com o agir do Estado, qual seja, a articulação das redes de serviço e a percepção dos profissionais, na vida prática esse empenho não parece garantir praticas de respeito à diversidade cultural.

A PNEVCM (133) de 2011 é o primeiro documento entre os estudados que se dirige diretamente à violência contra a mulher indígena e o faz por meio de eixos que apontam para a necessidade de produção de dados que refletiam a extensão e natureza do problema e para a ampliação e o fortalecimento da rede de serviçospara mulheres em situação de violênciavisando abarcar as mulheres indígenas, mas do ponto de vista da avaliação das ações iniciadas em 2007, quando da primeira versão do Plano, relata apenas a capacitação dos atendentes da Central Telefônica de Atendimento à Mulher para lidarcom as especificidades das mulheres indígenas, o que parece muito pouco diante da gravidade do problema.

Já a PNPM (134) traz entre suas metas uma proposição que reputamos como a estratégia mais interessante entre as que estão descritas no conjunto de enunciados das políticas e programas estudados: a instituição de fóruns de mulheres indígenas como forma de desenvolver estratégias culturalmente adequadas ao enfrentamento da violência de gênero.

Pode-se concluir pela possibilidade de que a publicação em 2006 da Lei Maria da Penha e o consequente aumento da discussão do problema pela sociedade como um todo influencioua abordagem por políticas e programas, uma 
vez que são exatamente as políticas e programas anteriores à lei que são completamente omissos em relação à questão à violência de gênero enquanto um problema de saúde pública.

De forma geral, a violência contra a mulher indígena nas políticas institucionais quando citadas encontram-se comprimidas em outras pautas. Não são propostas ações efetivas capazes de alcançar nessas mulheres, como reestruturação de redes oferecidas pelo estado ou apoio a processos de construção de mecanismos intracomunitários de vigilância e assistência. Assim, se de um lado o Estado se apropria e começa a abrir espaço para o discurso da interculturalidade em seus documentos oficiais, por outro lado continua a agir política econômica e socialmente em favor dos interesses coloniais que destroem as formas de vida cotidianas dos diversos povos.

Segato (135)chama a atenção para uma "propensão generalizada" ao engano, provocado pelo discurso colonial universalizante da modernidade, o qual nos conduz a uma crença acrítica no Estado, suas instituições e leis. Ela se refere a uma "frente estatal-empresarial-midiática-cristã sempre colonial" que continua avançando sobre as comunidades indígenas na América Latina, o que faz com que os esforços do Estado e seus agentes para elaboração de leis, políticas públicas e outras ações de proteção estejam sempre a reboque do próprio processo de destruição que esse mesmo Estado opera sobre essas comunidades. Nesse sentido,esta autora aposta na formação de mecanismos intracomunitários de proteção baseados em valores intrínsecos pertencentes ao "mundo-aldeia",que é como ela define as relações sociais intrínsecas dos povos indígenas antes da invasão colonial que se estruturou no percurso histórico entre a dominação ultramarina europeia e a constituição republicana dos chamados Estados ditos modernos na América Latina, dentro do qual a própria tomada dos corpos das mulheres constituiu um elemento estratégico da dominação e é responsável por grande parte das violências que hoje elas vivenciam.

Estudos internacionais envolvendo países com parcelas significativas de população indígena, como Canadá e Austrália, também têm demonstrado a relação estreita entre os processos de dominação colonial da ordem capitalista global e a destruição das relações e papéis sociais tradicionais de gênero. Kuokkanen (9) exemplifica a migração nesses dois países de mulheres de seus territórios para 
zonas urbanas em busca de sobrevivência, o que as tornam sujeitas ao encontro com o comércio de sexo. Essa autora argumenta que a violência de gênero que não parecia se constituir em um problema para os povos autóctones antes da colonização sofre uma profunda modificação a ponto de hoje no Canadá as mulheres índias terem cerca de 3,5 mais chances de serem vitimas de algum tipo de violência que as mulheres não índias e na Austrália esta chance chega a ser 45 vezesmaior.

O estudo de Burnette(8) sobre o serviço formal de atendimento às mulheres vítimas de violência nos Estados Unidos mostrou que os agentes do Estado em exercício não compreendiam as experiências da violência nem as condições históricas de opressão e discriminação vivenciadas pelas mulheres indígenas e apontou como os principais problemas do sistema a demora na resposta às denuncias de violências, a falta de confidencialidade e uma tendência à proteção aos perpetradores das práticas de violência. Segundo essa autora, a falta de amparo jurisdicional tem levado as mulheres índias a buscarem outros meios de amparo fora do sistema formal de proteção principalmente por entenderem que suas relações organizacionais são baseadas em comunidade onde "everyone is related to everybody'. Zimermaan, Saraguza e Viana (14) também indicaram ao estudar relatos de mulheres guarani e kaiowáem Mato Grosso do Sul a importância das relações de parentesco e articulações comunitárias na resolução de conflitos internos.

O aparato jurídico-institucional ainda não expressa sensibilidade ao universo particularizado da diversidade cultural e das mulheres indígenas, persistindo em tratar pela régua da universalização. O fato é que muitos desses meios de controle do Estado tendem inclusive a naturalizar a violência contra a mulher indígena como um elemento equivocadamente considerado enquanto característica cultural. Do outro lado, agentes dos poderes judiciários podem simplesmente ignorar o problema, como demonstrou o estudo de Silveira e Nardi (75) que entrevistou juízes do Poder Judiciário de Porto Alegre.

Essa indisposição à solidariedade e visibilidade do problema pelas redes de proteção e apoio às mulheres vítimas de violência influencia as relações destas com as mulheres indígenas, as quais acabam não as reconhecendo enquanto espaços legítimos de acolhimento aos seus problemas. A ausência de registros e 
informações referentes a essas mulheres, seja nas notificações dos serviços de saúde, seja nas ocorrências policiais, como apresentado por alguns dos artigos que compuseram a presente revisão, sugerem esse distanciamento, o qual também foi reconhecido pelo próprio plano nacional de enfrentamento à violência contra as mulheres.

Essa realidade de pouca visibilidade científica, política e institucional da violência contra a mulher indígena no Brasil convive com o clamor dessas mesmas mulheres por ações estratégicas do Estado para ajudá-las a enfrentar a violência por elas vivenciada. Elas têm demonstrado uma compreensão das agressões infringidas por seus parceiros como em grande parte induzidas pelos males do mundo nãoíndio, como o alcoolismo, as drogas e a convivência deles com a cultura violenta da sociedade comum.Em outro relato de resultados de grupos de discussão em Mato Grosso, as mulheres indígenas afirmaram que o álcool tem sido o grande responsável pelas agressões nas aldeias,pois"o homem bêbado é capaz de bater em qualquer mulher que ver pela frente, seja sua mãe seja sua mulher ou filha"(12).

Segundo Segato(136) o papel do Estado deveria ser o de restituir e garantir direitos étnicos e comunitários, devendo oportunizar aos povos a restauração de seus laços perdidos em decorrência da colonização. Não se trata da ausência do Estado, e sim construção de um Estado Pluralista que "na pessoa dos seus agentes, terá de ser o de estar disponível para supervisionar, mediar e interceder com o fim único de garantir que o processo interno de deliberação possa ocorrer livremente, sem abusos por parte dos mais poderosos no interior da sociedade.".

Segato aposta na capacidade de as mulheres indígenas administrarem sua soberania sexual e reprodutiva e a constituição de suas relações de gênero, tornando-se a principais propositoras dos caminhos de proteção. Para isso, faz-se necessário suspender os parâmetrospor meio dos quais o Estado estabelece as normativas positivas de uma cultura.É nesse sentido que o apoio à realização de fóruns de mulheres indígenas, como proposto no PNPM de 2013, parece constituir a proposta que mais se aproxima de uma construção descolonial de solução ao problema. Entretanto, fica clara a necessidade de enfrentar a situação de negligência científica sobre o problema com editais específicos para aprodução de estudos etnográficos envolvendo especificamente o problema, com o intuito de subsidiar tomadas de decisões que envolvam incontornavelmente as interações 
entre leis, políticas e serviços do Estado de proteção à violência de gênerocom a diversidade de contextos culturais de nossos povos autóctones. 


\section{CONSIDERAÇÕES FINAIS}

A crueldade e o desamparo às mulheres vítimas de violência aumentam conforme avança a concepção de Estado moderno e o livre mercado, até porque os protagonistas nessas estruturas são representados pelo poder masculino e pelos interesses de hierarquização decorrentes do projeto de dominação.

Ao avaliar o panorama de negligência de estudos científicos e da invisibilidade nos sistemas políticos-institucionais, comprova-se uma grande lacuna a ser preenchida com novos estudos sobre violência de gênero relacionada às mulheres indígenas e novas propostas para mecanismos de formulação de soluções culturalmente mediadas.

A discrepância entre as regiões de realização dos estudos que abordaram as questões interculturais e indígenas e os estados com maiores populações indígenas é reflexo da própria assimetria de desenvolvimento científico das diversas regiões do país, o que pode, em certa medida, ser interpretada como fenômenos coloniais internos em relação à produção de saber.

O presente trabalho apontou para a necessidade de construções descoloniais de caminhos plurais tanto para o campo científico quanto para as políticas públicas, leis e redes de proteção institucionais, o que implica também uma dimensão ética da abertura de espaços de diálogos interculturais com olhar transformador sobre as estruturas e as relações sociais de gênero.

Obviamente a presente revisão tem limitações, uma vez que se restringiu a apenas duas bases de dados, ainda que sejam as que indexam os principais periódicos nacionais e latino-americanosno campo da saúde, o que torna necessária a ampliação futura do presente estudopara outras bases nacionais e internacionais. Ainda que se considerem esses limites, não deixa de ser significativa a enorme diferença entre os 570 artigos iniciais encontrados com descritores restritos à violência de gênero em geral e um único artigo quando esses descritores foram cruzados com aqueles referentes aos povos indígenas. A aridez da produção específica é espantosa.

A bioética é um campo de análise e manifestações críticas relacionadas ao fenômeno da vida, nos espaços de discussão tem sido elemento de diálogo 
aprofundado o respeito à diversidade cultural e ao pluralismo ético, por meio da aceitação da existência de numerosos grupos étnicos, raciais, religiosos ou culturais distintos dentro de uma unidade social, organização ou população.

Com efeito, este solo fértil permite a concretização de proposição que desnudem essa invisibilidade científica e política da violência de gênero contra mulheres indígenas tal como: a inserção das discussões nas graduações e pósgraduações tanto na bioética como em saúde pública; desenvolvimento de editais para estudos etnográficos e de mobilização da sociedade ao combate, produção de materiais de conscientização sobre o problema que se debrucem sobre a violência de gênero em mulheres indígenas; ampliação de estudos em boletins de ocorrência focando os registros de mulheres indígenas e especialmente, a promoção de espaços e fóruns de mulheres para pensar ações e redes de saberes e de proteção intracomunitárias adequadas culturalmente para elas. 


\section{REFERÊNCIAS}

1. Waiselfisz JJ. Mapa da violência 2015: homicídios de mulheres no Brasil. Brasília: Flacso; 2015.

2. Compromisso e Atitude. Compromisso e Atitude pela Lei Maria da Penha. Dados e estatísticas sobre a violência contra as mulheres. Campanha. Disponível em:http://www.compromissoeatitude.org.br/dados-e-estatisticassobre-violencia-contra-as-mulheres/

3. Presidência da República (BR). Secretaria de Políticas para as Mulheres Balanço 2014 - Ligue 180 - Central de Atendimento à Mulher. Brasília; 2014.

4. Garcia LP, Freitas LRS, Silva GDM, Höfelmann AD. Violência contra a mulher: feminicídios no Brasil. Brasília: Instituto de Pesquisa Econômica Aplicada; 2013.

5.

Presidência da República (BR). Secretaria de Políticas para as Mulheres. Plano Nacional de Políticas para as Mulheres. Brasília: Secretaria de Políticas para as Mulheres; 2013.

6. Lorenzo, CFG. Vulnerabilidade em Saúde Coletiva: implicações para as políticas públicas. Revista Brasileira de Bioética, vol. 2, num 3, 2006.

7. Segato RL. El sexo y la norma: frente estatal, patriarcado, desposesión, colonialidad. Estudos Feministas. 2014 maio-ago; 22(2): 593-616.

8. Burnette CE. From the ground up: indigenous women's after violence experiences with the formal service system in the United States. British Journal of Social Work.2015; 45: 1526-45.

9. Kuokkanen R. Globalization as racialized, sexualized violence: the case of indigenous women. International Feminist Journal of Politics. 2008 Jun; 10(2): 216-33.

10. Hargreaves A. Colonial violence and the narrative imperative in feminist antiviolence discourse and indigenous women's riting. Canadian Woman studies/Les Cachiers de la femme. 2009; 27(2,3).

11.1 $1^{\text {a }}$ Assembléia das Guerreiras Mulheres Indígenas do Leste e Nordeste. Conselho Missionário Indigenista - CIMI. Disponível em:http://cimi.org.br/site/pt-br/?system=news\&action=read\&id=2709 
12. Torres MS. Um olhar sobre a violência intrafamiliar em aldeias karajá. In: Fazendo gênero 9:diásporas, diversidade, deslocamentos. 2010 ago. 23 a 26 Florianópolis.

13. Souza EL, Aleixo MT, Ruffeil MB. Maria(s) diversas, Pen(h)as diferentes: entre violências domésticas, gênero e diversidade cultural. In: Fazendo Gênero 9:diásporas, diversidades, deslocamentos. 2010 ago. 23 a 26 Florianópolis.p. 3.

14.Zimmermann TR, Seraguza L, Viana AEA. Relações de gênero e violência contra mulheres indígenas em Amambai-MS (2007-2013). Espaço Ameríndio. 2015 jan.-jul.; 9(1): 105-26.

15. Tovar-Restrepo M, Irazábal C. Indigenous women and violence in Colombia:agency, autonomy, and territoriality. Disponívelem: http://lap.sagepub.com/content/41/1/39.abstract

16. Lorenzo, CFG. Teoria crítica e bioética: um exercício de fundamentação. IN: Bioéticas, poderes e injustiças: 10 anos depois/Coordenação de Dora Porto, Volnei Garrafa, Gerson Zafalon Martins e Swenderberger do Nascimento Barbosa. Brasília: CFM/Cátedra Unesco de Bioética/SBB; 2012. 396 p. (173189)

17. Kottow M. Aspectos didácticos em bioética intercultural. Revista Brasileira de Educação Médica. vol.35 n‥2 Rio de Janeiro abril/jun. 2011.

18.Garrafa V. Kottow M. Saada, Ayla. (Org). Bases conceituais da bioética: enfoque latino-americano. Campanário. São Paulo: Gaia. 2006.

19. Health, Empowerment, Rightsand Accountability - HERA. Disponível em: https://iwhc.org/article/nossa-historia-nas-nacoes-unidas/

20.Guimarães MC, Pedroza RL.. Violência contra a mulher: problematizando definições teóricas, filosóficas e jurídicas. Psicol. Soc. [online]. 2015, vol.27, n.2, pp. 256-266.

21. Rinaldi AA. Violência e gênero - $A$ construção da mulher como vítima e seus reflexos no Poder Judiciário: a lei Maria da Penha como um caso exemplar. Disponível em: http://www.estacio.br/publicacoes/direitovivo/pdf/Artigo_Menezes.pdf

22. Scavone L. Estudos de gênero: uma sociologia feminista? Estudos Feministas, Florianópolis, 16(1): 288, janeiro-abril/2008.

23. Debert GG,Gregori MF. Violência de Gênero: novas propostas novos dilemas. RBCS Vol. 23 n‥ 66 fevereiro/2008 
24. Lei o 11.340 de 7 de agosto de 2006 que Cria mecanismos para coibir a violência doméstica e familiar contra a mulher. Disponível em: http://www.planalto.gov.br/ccivil_03/_ato2004-2006/2006/lei/111340.htm

25. Segato RL. Genero y Colonialidad: en busca de claves de lectura y de umvocabulário estratégico descolonial. Disponível em: http://nigs.ufsc.br/files/2012/09/genero_y_colonialidad_en_busca_de_claves_ de_lectura_y_de_un_vocabulario_estrategico_descolonial_ritasegato.pdf

26. Verdum R. (organizador). Mulheres Indígenas, Direitos e Políticas Públicas/Ela Wiecko. V. de Castilho .... [et al]. - Brasília: Inesc, 2008. 96p.

27.Lei o 13.104/2015 - Lei do Feminicídio que Altera o Código Penal, para prever o feminicídio como circunstância qualificadora do crime de homicídio, e para incluir o feminicídio no rol dos crimes hediondos. Disponível em:

28. Carissimi FSO. Movimentos Sociais e a Violência Contra As Mulheres do Campo: (In)Certezas De Uma Trajetória. Seminário Internacional Fazendo Gênero 10 (Anais Eletrônicos), Florianópolis, 2013. ISSN 2179-510X

29. Rede Nacional Feminista de Saúde e Direitos Reprodutivos - Regional Pernambuco Dossiê Violência contra Mulheres. Disponível em: http://www.redesaude.org.br/trilhas/docs/04a11.pdf

30. Texto base do $8^{\circ}$ Encontro Nacional de Mulheres da CUT, 27 a 29 de março de 2015.2 Disponível em :http://www.cut.org.br/system/uploads/action_file_version/da0b316e51865231 b80ef2f3f508d0e5/file/af-publicacao-texto-base-8-encontro-nacional-dasmulheres-da-cut.pdf

31.Saúde da mulher negra: guia para a defesa dos direitos das mulheres negras. Porto Alegre, 2012 Disponível em: http://www.amnb.org.br/admin/biblioteca/Relat\%C3\%B3rio\%20Saude.PDF

32. ONU. Convenção sobre a eliminação de todas as formas de discriminação contra a mulher http://www.observatoriodegenero.gov.br/eixo/internacional/instancias-

(1979). regionais/o-comite-cedaw-2013-comite-para-a-eliminacao-de-todas-asformas-de-discriminacao-contra-a-mulher

33. Comissão Interamenricana de Direitos Humanos. Convenção interamericana para prevenir, punir e erradicar a violência contra a mulher, "Convenção de Belém do Pará". http://www.cidh.org/Basicos/Portugues/m.Belem.do.Para.htm

34.Pesquisa Instituto AVON/IPSOS. Estudo percepções sobre a violência doméstica contra a mulher no Brasil 2011. Disponível em:

35. Instituto Brasileiro de Geografia e estatística - IBGE. CENSO 2010. Disponível em: http://indigenas.ibge.gov.br/graficos-e-tabelas-2 
36. Instituto Brasileiro de Geografia e estatística - IBGE. Os indígenas no Censo Demográfico 2010. Rio de Jeneiro, 2012. Acesso em: 03 mar.2015. Disponível

em: http://indigenas.ibge.gov.br/images/indigenas/estudos/indigena censo2010.pd f

37. Kymlicka W. Direitos humanos e justiça etnocultural.Meritum - Belo Horizonte - v. 6 - n. 2 - p. $13-55$ - jul./dez. 2011

38. Horkheimer M. Teoría Crítica. Amarrortu editores. Buenos Aires-Madrid. 2003.

39.Freitag B. A teoria crítica: ontem e hoje. São Paulo: Brasiliense.1986.

40.Benjamin W. Teses sobre o conceito da história. Tese 14. In: Benjamin W. Obras escolhidas. Magia e técnica, arte e política. Ensaios sobre literatura e história da cultura. São Paulo: Brasiliense, 1987.

41. Nobre M. Max Horkheimer, a teoria crítica entre o nazismo e o capitalismo tardio. In: Nobre M. Curso Livre de Teoria Crítica. 3 ed. Papirus editora. Campinas: Papirus editora. 2011:35-52

42. Terra R. Herbert Marcuse, os limites do paradigma da revolução: ciência, técnica e movimentos sociais. In: Nobre M. Curso Livre de Teoria Crítica. 3 ed. Campinas: Papirus editora. 2011:137-160.

43. Habermas J. Direito e democracia: entre faticidade e validade. 2. ed. Rio de Janeiro: Tempo Brasileiro, 1997.

44. Habermas J. O discurso filosófico da modernidade: doze lições: São Paulo: Martins Fontes. 2000.

45. Quijano A. Colonialidade do poder, Eurocentrismo e América Latina. In: A colonialidade do saber: eurocentrismo e ciências sociais. Perspectivas latinoamericanas. Buenos Aires. CLACSO, ConsejoLatinoamericano de CienciasSociales. 2005.

46. Nascimento, WF; Garrafa, V. Por uma vida não colonizada: diálogo entre bioética de intervenção e colonialidade. Saúde e SOc. São Paulo, v.20, n.2, p.287-299, 2011.

47. Nascimento WF, Martorell LB. A bioética de intervenção em contextos descoloniais. Rev. bioét. (Impr.). 2013;21(3):423-31:430.

48.Palermo Z. Quintero, P. Aníbal Quijan La perspectiva de la Colonialidade del poder. Prefácio Textos de Fundación. Buenos Aires: Edicionesdel Signo, Colección Eldesprendimiento, 2014.Pg. 7-11 
49. Walsh, C. Interculturalidad y Educación Intercultural. Instituto Internacional de Integración del Convenio Andrés Bello. La Paz, 2009.

50.Segato, RL.. Antropologia e direitos humanos: alteridade e ética no movimento de expansão dos direitos universais. Mana, 12(1), 207-236. (2006)

51. Oliveira AAS. Bioética e direitos humanos: tratamento teórico da interface. Revista de Direito Sanitário, São Paulo v. 11, n. 1 p. 65-94 Mar./Jun. 2010.

52. Oliveira AAS. Perspectiva bioética intercultural e direitos humanos. Rev. bioét. (Impr.). 2015; 23 (1): 80-8

53. Declaração Universal sobre Bioética e Direitos Humanos. Cátedra UNESCO de Bioética da Universidade de Brasília. Disponível em: http://unesdoc.unesco.org/images/0014/001461/146180por.pdf

54.Bandeira LM. Almeida, TMC. Bioética e feminismo: um diálogo em construção. Revista Bioética 200816 (2): 173 - 89

55.Diniz D. Vélez ACG. Bioética Feminista:a emergência da diferença. Artigo apresentado no II Feminist Approaches in Bioethics, realizado em TsukubaJapão, entre os dias31 de outubro e 03 de novembro de 1998.

56. Wolf SM. Feminist and Bioethcs: beyond reproducion. New York Oxford Uniiversity press, 1996.

57.Diniz D. Bioética e gênero. Revista Bioética 200816 (2): 207 - 16

58. Broome ME. Integrative literature reviews for the development of concepts. IN: Concept development in nursing: foundations, techiniques and applications. Second edition. W.B Saunders Company. 2000.

59. Whittemore R. Knalf $\mathrm{K}$. The integrative review: update methodology. J AdvNurs. 2005;52(5):546-53. 


\section{Referências dos artigos achados}

60. Okabe I. Fonseca, RMGS. Violência contra a mulher: contribuições e limitações do sistema de informação. Rev. esc. enferm. USP [online]. 2009, vol.43, n.2, pp. 453-458.

61. moreira, TNF; Martins, CL,Feuerwerker, LCM, Schraiber, LB. A construção do cuidado: o atendimento às situações de violência doméstica por equipes de Saúde da Família. Saude soc. [online]. 2014, vol.23, n.3, pp. 814-827.

62. Guedes RN; Fonseca RMGS, Egry, EY. Limites e possibilidades avaliativas da estratégia saúde da família para a violência de gênero. Rev. esc. enferm. USP [online]. 2013, vol.47, n.2, pp. 304-311.

63. Oliveira, RNG, Fonseca RMGS. Necessidades em saúde: a interface entre o discurso de profissionais de saúde e mulheres vitimizadas. Rev. Latino-Am. Enfermagem [online]. 2015, vol.23, n.2, pp. 299-306.

64. Hanada H; D'Oliveira AFPL, Schraiber, LB. Os psicólogos na rede de assistência a mulheres em situação de violência. Rev. Estud. Fem. [online]. 2010, vol.18, n.1, pp. 33-60.

65. Sousa $\mathrm{MH}$, et a. Preenchimento da notificação compulsória em serviços de saúde que atendem mulheres que sofrem violência sexual. Rev. bras. epidemiol. [online]. 2015, vol.18, n.1, pp. 94-107.

66. Schraiber, LB; Barros CRS, Castilho EA. Violência contra as mulheres por parceiros íntimos: usos de serviços de saúde. Rev. bras. epidemiol.[online]. 2010, vol.13, n.2, pp. 237-245

67. Gomes NP, et al. Cuidado às mulheres em situação de violência conjugal: importância do psicólogo na Estratégia de Saúde da Família. Psicol. USP [online]. 2014, vol.25, n.1, pp. 63-69. 
68. Silva EB; Padoin SMM; Vianna LAC.Violência contra a mulher: limites e potencialidades da prática assistencial. Acta paul. enferm; 26(6): 608-613, 2013.

69. Escorsim SM. Violência de gênero e saúde coletiva: um debate necessário. Rev. katálysis [online]. 2014, vol.17, n.2, pp. 235-241.

70. Bandeir LM. Violência de gênero: a construção de um campo teórico e de investigação. Soc. estado.[online]. 2014, vol.29, n.2, pp. 449-469. ISSN $0102-$ 6992.

71.Schraiber LB, D' Oliveira AFPL, Portella, AP, Menicucci, E. Violência de gênero no campo da Saúde Coletiva: conquistas e desafios. Ciênc. saúde coletiva[online]. 2009, vol.14, n.4, pp. 1019-1027.

72.Schraiber LB, D' Oliveira AFPL, Portella AP, Couto MT. Violência e saúde: contribuições teóricas, metodológicas e éticas de estudos da violência contra a mulher. Cad. Saúde Pública [online]. 2009, vol.25, suppl.2, pp. s205s216.

73.D' Oliveira AFPL, Schraiber LB. Mulheres em situação de violência: entre rotas críticas e redes intersetoriais de atenção. RevMed (São Paulo). 2013 abr.-jun.;92(2):134-40.

74. Silveira RS, Nardi, HC, Spindler G. Articulações entre gênero e raça/cor em situações de violência de gênero. Psicol. Soc. [online]. 2014, vol.26, n.2, pp. 323-334. ISSN 1807-0310.

75. Silveira RS, Nardi HC. Interseccionalidade gênero, raça e etnia e a lei Maria da Penha. Psicologia \& Sociedade; 26(n. spe.), 14-24.

76. Medrado B.; Méllo, R. P. "Posicionamentos críticos e éticos sobre a violência contra as mulheres" Psicologia \& Sociedade; 20, Edição Especial: 78-86, 2008.

77.Pougy LG. Desafios políticos em tempos de Lei Maria da Penha,. Rev. katálysis [online]. 2010, vol.13, n.1, pp. 76-85. 
78. Menezes PRM, et al. Enfrentamento da violência contra a mulher: articulação intersetorial e atenção integral. Saude soc. [online]. 2014, vol.23, n.3, pp. 778786.

79. Santos MS, Vieira EM. Recursos sociais para apoio às mulheres em situação de violência em Ribeirão Preto, SP, na perspectiva de informanteschave. Interface (Botucatu) [online]. 2011, vol.15, n.36, pp. 93-108.

80. Acosta DF; Gomes VLO; Fonseca AD, Gomes GC. Violência contra a mulher por parceiro íntimo: (in)visibilidade do problema. Texto contexto enferm. [online]. 2015, vol.24, n.1, pp. 121-127.

81. Amaral, NA; Amaral CA, Amaral TLM. Mortalidade feminina e anos de vida perdidos por homicídio/agressão em capital brasileira após promulgação da Lei Maria da Penha. Texto contexto - enferm. [online]. 2013, vol.22, n.4, pp. 980-988.

82. Osis MJD; Duarte GA,FaundesA.Violência entre usuárias de unidades de saúde: prevalência, perspectiva e conduta de gestores e profissionais. Rev. Saúde Pública [online]. 2012, vol.46, n.2, pp. 351-358.

83. MeneghelSN,Hirakata VN. Femicídios:homicídios femininos no Brasil. Rev. Saúde Pública [online]. 2011, vol.45, n.3, pp. 564-574. ISSN 0034-8910.

84. Schraiber LB, et al. Prevalência da violência contra a mulher por parceiro íntimo em regiões do Brasil. Rev. Saúde Pública[online]. 2007, vol.41, n.5, pp. 797-807.

85. Vieira LJES, et al. Fatores associados à sobreposição de tipos de violência contra a mulher notificada em serviços sentinela. Rev. Latino-Am. Enfermagem [online]. 2013, vol.21, n.4, pp. 920-927.

86. Ilha MM; Leal SMC, Soares JSF. Mulheres internadas por agressão em um hospital de pronto socorro: (in)visibilidade da violência. Rev. Gaúcha Enferm. (Online) [online]. 2010, vol.31, n.2, pp. 328-334.

87.Gadoni-Costa LM, Zucatti APN, Dell'aglio DD. Violência contra a mulher:levantamento dos casos atendidos no setor de psicologia de uma delegacia para a mulher. Estud. psicol. (Campinas) [online]. 2011, vol.28, n.2, pp. 219-227. 
88. Meneghel SN, Ceccon RF; Hesler LZ, Margarites AF, Rosa S, Vasconcelos VD. Femicídios: narrativas de crimes de gênero. Interface comun. saúdeeduc; 17(46): 523-533, jul.-set. 2013.

89.Sllva RA, Araújo TVB,Valongueiro S, Ludermir AB. Enfrentamento da violência infligida pelo parceiro íntimo por mulheres em área urbana da região Nordeste do Brasil. Rev. Saúde Pública [online]. 2012, vol.46, n.6, pp. 10141022.

90.Gomes NP, Diniz NMF, Reis LA, Erdmann AL. Rede social para o enfrentamento da violência conjugal: representações de mulheres que vivenciam o agravo. Texto contexto - enferm. [online]. 2015, vol.24, n.2, pp. 316-324.

91.Vieira LB, Souza, IEO, Tocantins FR,Pina-Roche F. Apoio à mulher que denuncia o vivido da violência a partir de sua rede social. Rev. Latino-Am. Enfermagem [online]. 2015, vol.23, n.5, pp. 865-873

92. Acosta DF, Gomes VLO, Barlem ELD. Perfil das ocorrências policiais de violência contra a mulher. Acta paul. enferm. [online]. 2013, vol.26, n.6, pp. 547-553.

93.Leite FMC, Bravim LR, Lima EFA et al. Violência contra a mulher: caracterizando a vítima, a agressão e o autor. Revista de Pequisa Cuidado é undamental On-Line. Universidade Federal do Rio de Janeiro. fundam. care. online 2015. jan./mar. 7(1):2181-2191

94.Leoncio KL, Baldo PL, MalundoJjoão V, Biffi RG. O PERFIL DE MULHERES VITIMIZADAS E DE SEUS AGRESSORES. Rev. enferm. UERJ, Rio de Janeiro, 2008 jul/set; 16(3):307-12.

95. Azevedo RG. Sistema penal e violência de gênero: análise sociojurídica da Lei 11.340/06. Soc. estado. [online]. 2008, vol.23, n.1, pp. 113-135. ISSN 0102-6992.

96. Maciel DA. Ação coletiva, mobilização do direito e instituições políticas: o caso da campanha da lei Maria da Penha.Rev. bras. Ci. Soc. [online]. 2011, vol.26, n.77, pp. $97-112$ 
97. Cortizo MC, Goyeneche PL. Judiciarização do privado e violência contra a mulher. Rev. katálysis[online]. 2010, vol.13, n.1, pp. 102-109.

98. Vieira EM, et al. Conhecimento e atitudes dos profissionais de saúde em relação à violência de gênero. Rev. bras. epidemiol. [online]. 2009, vol.12, n.4, pp. 566-577.

99. Silva EB, Padoin, SMM,Vianna LAC. Violência contra a mulher e a prática assistencial na percepção dos profissionais da saúde. Texto contexto enferm. [online]. 2015, vol.24, n.1, pp. 229-237.

100. RODRIGUES, Vanda Palmarella et al. Prática de trabalhadora(e)s de saúde na atenção às mulheres em situação de violência de gênero.Texto contexto - enferm. [online]. 2014, vol.23, n.3, pp. 735-743.

101. Gomes NP, et al. Identificação da violência na relação conjugal a partir da Estratégia Saúde da Família. Texto contexto - enferm. [online]. 2013, vol.22, n.3, pp. 789-796

102. Hasse M, Vieira EM. Como os profissionais de saúde atendem mulheres em situação de violência? Uma análise de dados. Saúde Debate. 2014 jul.; 38(102): 482-96.

103. Pedrosa CM, Spink MJP. A violência contra mulher no cotidiano dos serviços de saúde: desafios para a formação médica. Saude soc. [online]. 2011, vol.20, n.1, pp. 124-135.

104. Moreira SNT, Galvão LLLF, Melo COM, Azevedo GD. Violência física contra a mulher na perspectiva de profissionais de saúde. Rev. Saúde Pública [online]. 2008, vol.42, n.6, pp. 1053-1059

105. Silva CD, et al. Representação social da violência doméstica contra a mulher entre Técnicos de Enfermagem e Agentes Comunitários. Rev. esc. enferm. USP [online]. 2015, vol.49, n.1, pp. 22-29.

106. Costa MC, Lopes MJM, Soares JSF. Representações Sociais Da Violência Contra Mulheres Rurais: Desvelando Sentidos Em Múltiplos Olhares. Rev. esc. enferm. USP [online]. 2014, vol.48, n.2, pp. 213-221. 
107. Costa MC, Lopes MJM, Soares JSF. Elementos de integralidade nas práticas profissionais de saúde a mulheres rurais vítimas de violência. Rev. esc. enferm. USP [online]. 2012, vol.46, n.5, pp. 1088-1095

108. LettiereA, Nakano AMS, Rodrigues DT. Violência contra a mulher: a visibilidade do problema para um grupo de profissionais de saúde. Rev. esc. enferm. USP[online]. 2008, vol.42, n.3, pp. 467-473.

109. Gomes NP, Erdmann AL. Violência conjugal na perspectiva de profissionais da "Estratégia Saúde da Família": problema de saúde pública e a necessidade do cuidado à mulher. Rev. Latino-Am. Enfermagem [online]. 2014, vol.22, n.1, pp. 76-84. ISSN 0104-1169.

110. Fonseca, RMGS, et al. Violência doméstica contra a mulher na visão do agente comunitário de saúde. Rev. Latino-Am. Enfermagem [online]. 2009, vol.17, n.6, pp. 974-980.

111. HeslerLZ,Costa, MC, Resta DG, Colome, ICS. Violência contra as mulheres na perspectiva dos agentes comunitários de saúde. Rev. Gaúcha Enferm.[online]. 2013, vol.34, n.1, pp. 180-186.

112. Vieira LB; PadoinSMM,Landerdahl, MC. A percepção de profissionais da saúde de um hospital sobre a violência contra as mulheres. Rev. Gaúcha Enferm. (Online)[online]. 2009, vol.30, n.4, pp. 609-616.

113. BaraldiACP, Almeida AM, Perdona GC, Vieira EM. Violência contra a mulher na rede de atenção básica: o que os enfermeiros sabem sobre 0 problema?. Rev. Bras. Saude Mater. Infant. [online]. 2012, vol.12, n.3, pp. 307-318.

114. Almeida LR, Silva ATMC, Machado, LS. Jogos para capacitação de profissionais de saúde na atenção à violência de gênero. Rev. bras. educ. med. [online]. 2013, vol.37, n.1, pp. 110-119.

115. Porto $M$. Violência contra a mulher e atendimento psicológico:o que pensam os/as gestores/as municipais do SUS. Psicol. cienc. prof. [online]. 2006, vol.26, n.3, pp. 426-439. 
116. Almeida LR, Silva ATMC, Machado, LS. O objeto, a finalidade e os instrumentos do processo de trabalho em saúde na atenção à violência de gênero em um serviço de atenção básica. Interface (Botucatu) [online]. 2014, vol.18, n.48, pp. 47-60.

117. Kiss LB, Schraiber LB, D'oliveira AFPL. Possibilidades de uma rede intersetorial de atendimento a mulheres em situação de violência. Interface (Botucatu) [online]. 2007, vol.11, n.23, pp. 485-501.

118. DE FERRANTE, Fernanda Garbelini; SANTOS, Manoel Antônio dos and VIEIRA, Elisabeth Meloni. Violência contra a mulher: percepção dos médicos das unidades básicas de saúde da cidade de Ribeirão Preto, São Paulo. Interface (Botucatu) [online]. 2009, vol.13, n.31, pp. 287-299.

119. Costa MC; Lopes MJM, Soares JSF. Violência contra mulheres rurais: gênero e ações de saúde. Esc. Anna Nery [online]. 2015, vol.19, n.1, pp. 162168.

120. Gomes NP, et al. Significado da capacitação profissional para o cuidado da mulher vítima de violência conjugal.Esc. Anna Nery [online]. 2013, vol.17, n.4, pp. 683-689.

121. Bonfim EG,Lopes MJM, Peretto M. Os registros profissionais do atendimento pré-natal e a (in)visibilidade da violência doméstica contra a mulher. Esc. Anna Nery [online]. 2010, vol.14, n.1, pp. 97-104.

122. Guedes RN, Fonseca RMGS. A autonomia como necessidade estruturante para o enfrentamento da violência de gênero. RevEscEnferm USP; 45(spe2): 1731-1735, dez. 2011.

123. Porto M, Costa FP. Lei Maria da Penha: as representações do judiciário sobre a violência contra as mulheres. Estudos de Psicologia I Campinas I 27(4) I 479-489 I outubro - dezembro 2010.

124. Silva LEL, Oliveira MLC. Violência contra a mulher: revisão sistemática da produção científica nacional no período de 2009 a 2013. Ciênc. saúde coletiva [online]. 2015, vol.20, n.11, pp. 3523-3532. 
125. Duarte MC, Fonseca RMGS, Souza V. Pena ED. Gênero e violência contra a mulher na literatura de enfermagem: uma revisão. Rev. Bras. Enferm. [online]. 2015, vol.68, n.2, pp. 325-332.

126. Instituto Brasileiro de Geografia e estatística. Características gerais dos povos indígenas no CENSO 2010. Disponível em: http://www.ibge.gov.br/home/estatistica/populacao/censo2010/caracteristicas_ gerais_indigenas/default_uf_xls.shtm

127. Heise L. Gender-based Abuse: the global epidemic. Cad. Saúde Pública. 1994; 10(1 suppl.). Disponível em:http://dx.doi.org/10.1590/S0102$\underline{311 \times 1994000500009}$

128. KindL,Orsini MLP, Nepomuceno V, Gonçalves L, Souza GA, Ferreira MFF. Subnotificação e (in)visibilidade da violência contra mulheres na atenção primária à saúde. Cad. Saúde Pública. 2013 set.29(9):1805-15.

129. Souza ER, Ribeiro AP, Penna LHG, Ferreira AL, Santos NC, Tavares CMM. O tema violência intrafamiliar na concepção dos formadores dos profissionais de saúde. Ciência \& Saúde Coletiva. 2009; 14(5):1709-19.

130. Quijano A. Colonialidade do Poder e Classificação Social. In: Santos BSS, Meneses MP, organizadores. Epistemologias do Sul. Coimbra: Edições Almedina; 2009. p.73-118.

131. Ministério da Saúde (BR), Fundação Nacional de Saúde. Política Nacional de Atenção à Saúde dos Povos Indígenas. 2. ed. Brasília: Ministério da Saúde; 2002. 40 p.

132. Ministério da Saúde (BR), Secretaria de Atenção à Saúde, Departamento de Ações Programáticas Estratégicas. Política Nacional de Atenção Integral à Saúde da Mulher: princípios e diretrizes. Brasília: Ministério da Saúde; 2004. 82 p.

133. Presidência da República (BR), Secretaria de Políticas para as Mulheres. Política Nacional de Enfrentamento à Violência contra as Mulheres. Brasília: Secretaria de Políticas para as Mulheres; 2011. 70 p.

134. Presidência da República (BR), Secretaria de Políticas para as Mulheres.Plano Nacional de Política para as Mulheres. Brasília: Secretaria de Políticas para as Mulheres; 2013. 114 p.

135. Segato RL. Las nuevas formas de la guerra y el cuerpo de las mujeres. Rev. Soc. Estado. 2014 maio-ago.; 29(2). 
136. Segato RL. Que cada povo teça os fios da sua história: o pluralismo jurídico em diálogo didático com legisladores. Revista de Direito da Universidade de Brasília. 2014 jan.jun.;1(1).

\section{Anexo I}

PLANILHA COM AS INFORMAÇÕES DOS ARTIGOS SELECIONADOS PARA ANÁLISE 